\title{
Work, Leisure, and Family: From the Silent Generation to Millennials
}

\author{
George-Levi Gayle, Mariana Odio-Zuniga, and Prasanthi Ramakrishnan
}

\begin{abstract}
This article analyzes the changes in family structure, fertility behavior, and the division of labor within the household from the Silent generation (cohort born in 1940-49) to the Millennial generation (cohort born in 1980-89). Using data from the Panel Study of Income Dynamics, this article documents the main trends and life-cycle profiles for each generation. The main findings are that (i) the wage-age profile has been shifting down over generations, especially for Millennial men; (ii) the returns to a four-year college degree or higher for men have increased for all generations; (iii) Millennials enjoy a higher level of leisure than previous generations; (iv) the housework hours for women have clearly declined over generations, while the housework hours for Millennial men are higher than those of the previous generations of men; (iv) less-educated individuals have retreated from marriage, especially Millennials, while more-educated individuals have delayed marriage; (v) divorce rates have risen, with Millennials most likely to divorce, but the longer a couple is married, the likelihood of divorce has decreased over generations; and (vi) the Millennials' completed fertility rate is likely to be the lowest among all generations. (JEL I0, I2, J0, J1, J3, J7 )
\end{abstract}

Federal Reserve Bank of St. Louis Review, Fourth Quarter 2021, 103(4), pp. 385-424. https://doi.org/10.20955/r.103.385-424

\section{INTRODUCTION}

Over the past half-century, some of the most striking socioeconomic changes in developed countries have been the radical changes in the family structure, fertility behavior, and the division of labor within the household. These changes have consequences for labor market productivity and the viability of Social Security and other programs. For example, the decline in fertility below the replacement rate has led to a major concern for pay-as-you-go social security in Organisation for Economic Co-operation and Development countries, including the United States. Moreover, the significant increase in the percentage of women in the workforce has had a considerable effect on the type of benefits employers offer, specifically regarding a family-friendly workplace, parental leave, and other work-family balance policies.

George-Levi Gayle is a professor of economics at Washington University in St. Louis and a research fellow at the Federal Reserve Bank of St. Louis. Mariana Odio-Zuniga and Prasanthi Ramakrishnan are PhD candidates at Washington University in St. Louis. The authors thank Limor Golan and Robert Pollak for helpful discussions.

(C) 2021, Federal Reserve Bank of St. Louis. The views expressed in this article are those of the author(s) and do not necessarily reflect the views of the Federal Reserve System, the Board of Governors, or the regional Federal Reserve Banks. Articles may be reprinted, reproduced, published, distributed, displayed, and transmitted in their entirety if copyright notice, author name(s), and full citation are included. Abstracts, synopses, and other derivative works may be made only with prior written permission of the Federal Reserve Bank of St. Louis. 


\section{Gayle, Odio-Zuniga, Ramakrishnan}

Several articles analyze the changes in the family structure, fertility behavior, and the division of labor within the household for older generations (see Eckstein, Keane, and Lifshitz, 2019; Kong, Ravikumar and Vandenbroucke, 2018; and Ramey and Francis, 2009); however, to the best of our knowledge, no study has analyzed these changes in the latest generationMillennials ${ }^{1}$ - and how their family, fertility, and labor market behavior compares with that of the previous generations. The scarcity of studies analyzing the behavior of Millennials is mainly because of a lack of data. Using data from the Panel Study of Income Dynamics (PSID) from 1968 to 2015, this article presents the first read on the behavior of Millennials as they complete their education, form their families, and transition into adulthood.

This article focuses on three key aspects: work, leisure, and family. For each of these, trends over time as well as life-cycle profiles over generations are presented. In addition to this, an Oaxaca-Blinder decomposition of wages into explained and unexplained components is estimated to understand the changes in the gender wage gap. Given the trends in education and the recent convergence in the wage gap, the returns to the labor market are also estimated and the changes are analyzed over generations by race and gender. Along with the changes in education and hours worked, there has been a major change in housework hours as well. Using a linear regression framework, as a first cut, the differential effects of education, race, gender, marital status, and the presence of children on housework hours are estimated. Lastly, with declining marriage rates, the key question of what predicts partner choice is analyzed using a multinomial logit model.

In the article, we assign the generations the following names and birth cohorts:

- Silent generation: 1940-49

- Baby Boomers-1 (Boomers-1): 1950-59

- Baby Boomers-2 (Boomers-2): 1960-69

- Generation X (GenX): 1970-79

- Millennials: 1980-89

Focusing on labor markets and education decisions, we find that the wage-age profile has been shifting down over generations, with Millennial men having the lowest real wages over

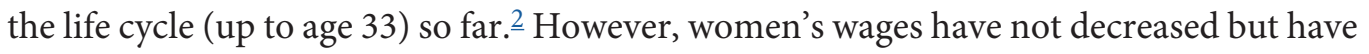
stagnated, with Millennial women earning lower wages than GenX for the part of the life cycle that can be analyzed (up to age 33). This finding indicates that most of the documented rise in wage inequality has come from men and not women. 3 For both Black men and White men, returns to college graduates (those with a four-year degree or higher) have increased for all generations, with the most significant increase for Millennials, specifically Black men. ${ }^{4}$

Despite the increasing returns to college for men, Black women have always graduated from college at higher rates than Black men; and this gap has only increased over the birth cohorts. On the other hand, up to Boomers-1, White men graduated from college at higher rates than White women; this gap reversed in Boomers-2 and has continued to increase over generations (see Goldin, Katz, and Kuziemko, 2006; Murnane, 2013; Blau and Kahn, 2017; and Eckstein, Keane, and Lifshitz, 2019), with Millennials having the biggest gap between White men and White women. While the college graduation gap between White men and 
White women is more than the college graduation gap between Black men and Black women, this outcome reverses if individuals with some college and college graduates are combined.

There has been a significant increase in college graduation rates for Boomers- 2 and GenX for both Blacks and Whites, a pattern that has continued to accelerate for White Millennials. This is in sharp contrast to the graduation rates for the Silent and Boomers-1 generations, which were generally stable across the two. Another striking feature of the change in the education distribution over the generations is the significant reduction in high school dropout rates; this has been most pronounced for Blacks. The percentage of Black high school dropouts fell from 27.5 percent for the Silent generation to 7.1 percent for the Millennial generation.

A few studies in the existing literature analyze leisure over generations and the life cycle. Three notable exceptions are Aguiar and Hurst (2007); Ramey and Francis (2009); and Aguiar, Hurst, and Karabarbounis (2012). This article finds that over generations, while the amount of leisure enjoyed by women has been increasing, the amount of leisure enjoyed by men shows no clear pattern. However, for both men and women, Millennials enjoy a higher level of leisure than previous generations. This rise in leisure for women is primarily coming from married women. Splitting the sample by education, this article finds that women who are college graduates enjoy less leisure than those who are high school graduates, and the same is true for men. The finding that the amount of leisure enjoyed by men is stable over generations masks different dynamics in the components of leisure. There has been a significant reduction in hours worked by men, with Millennials working the least. At the same time, there has been an increase in the housework hours for men, with Millennial men devoting more hours to housework than men of any previous generation. The opposite is true for women: Their reduction in hours devoted to housework over generations has been more than offset by the increase in hours devoted to market work. More importantly, most of this movement has happened within married couples.

The findings of this article are in contrast to Aguiar and Hurst's (2007), who find that leisure is increasing for everyone. Several factors may account for these conflicting results. First, different data sources are used in this article. Second, this article compares leisure over generations and the life cycle, while they do not. Third, the measure of leisure used here may not coincide with the measure of leisure they use, as they are using self-reported data from time diaries, whereas the measure in this article is the residual of hours worked in the market and in household production. Because of these differences, the measure of leisure used in this article is more comparable with the measure used in Ramey and Francis (2009), and results here confirm the life-cycle analysis reported in that article.

The media has often conjectured that the marriage, cohabitation, divorce, and fertility behaviors of Millennials are radically different from previous generations. A detailed analysis of these behaviors is provided, which has been lacking so far. Marriage (and, thus, fertility) has seen many drastic changes over generations. Lower-educated individuals have retreated from marriage, $\underline{5}$ and this finding is the most pronounced among Millennials. However, while Millennial college graduates are delaying marriage significantly, they do catch up with previous generations by ages 30 to 33. Thus, it is not clear whether Millennials would be marrying at an overall rate lower than previous generations, as the composition of education has also 


\section{Gayle, Odio-Zuniga, Ramakrishnan}

changed, with a much higher number of college graduates among Millennials. No clear trends in assortative matching are found over generations. Although this is in contrast to the findings of Greenwood and Guner (2008) and Santos and Weiss (2016), it is in line with those of Gihleb and Lang (2016). However, Millennials are cohabiting at a much higher rate than previous generations. For GenX and Millennials, cohabitation rates are much higher early on in life relative to previous generations; however, the rates drop off significantly after that, indicating cohabitation itself is transitory. This was not true for the Silent and Boomer generations. With respect to divorce, the Silent generation has a fairly flat profile over the number of years since marriage. The subsequent generations present rising divorce rates and more pronounced duration dependence; that is, as the length of the marriage increases, the likelihood of divorce decreases, with Millennials having the highest probability of divorce after five years of marriage. The major changes across generations in divorce rates are primarily coming from Blacks and couples where at least one spouse has completed education of less than or equal to a high school diploma. Couples where both spouses have completed some college or more have significantly lower divorce rates, as also documented by Lundberg, Pollak, and Stearns (2016).

Finally, concerning fertility trends, the significant decline in completed fertility is confirmed in this article, with Boomers- 2 and GenX fertility rates falling below the replacement rate. Similar trends exist across race. ${ }^{6}$ There has been a steady decline across generations at each age parity of the proportion of births to married women, although this decline has accelerated among Millennials. For example, the proportion of births to married women ages 31 to 35 for the Silent generation is 88 percent, which fell to 83 percent for GenX and even further to 75 percent for Millennials. The age-specific fertility rate has declined for every generation up to GenX. Fertility rates for Millennial women ages 18 to 30 are below every previous generation's; however, for Millennial women ages 31 to 35, the fertility rate is higher than for GenX women of the same ages. This finding suggests that the completed fertility rate for Millennials may not necessarily be below that for GenX; although Millennials are delaying fertility, their fertility rates at later ages might be higher than those of the immediate previous generation.

The remainder of the article proceeds as follows. Section 2 describes the construction of our primary dataset from the PSID. Section 3 presents trends related to education, hours worked, and wages over time as well as by generation. Section 4 details the changes in housework hours and leisure hours over time and by generation. Section 5 delves into time and generation trends for fertility, marriage, and divorce. Finally, Section 6 concludes.

\section{DATA}

The main dataset used in this analysis is constructed using various files from the PSID. The PSID is a nationally representative household panel survey that includes economic, social, and health information from 1968 to 2015. This survey was conducted annually from 1968 to 1997 and biannually thereafter. To compile the dataset, we used the family-individual files, marriage history files, childbirth and adoption history files, and the T-2 income and transfers files. The latter helps to complete the information regarding labor income and annual hours 
worked in the intervening years during the periods when the survey is conducted biannually. The final sample used in this study contains data on individuals ages 18 to 65, resulting in 38,958 unique individuals and 505,496 individual-year observations.

The employment rate is defined as the fraction of individuals with annual labor market hours greater than zero. Hourly wages are defined as the sum of labor income, farming income, and business income divided by the annual labor market hours worked. All nominal values are deflated to 2015 U.S. dollars using the consumer price index deflator.

The marriage history file contains information regarding individuals' marital status from 1901 to 2015. The variable "legally married" is taken directly from this file. The PSID separately documented from 1983 onward if the head of the household has a "wife" (cohabiting but not married) for more than a year. Prior to 1983, both a legally married wife and a cohabiting "wife" were grouped without distinction. This presents an issue in constructing a consistent measure for cohabitation. Hence, the marriage information from the marriage history file is used and compared with the marital pairs indicator-whether or not there exists a marital pair in the household from the family-individual file. If the head is not legally married and there exists a marital pair in the household, it is assumed that they are cohabiting. This measure is fairly comparable with the measure constructed from the post-1983 data.

\section{WORK}

\subsection{Education}

Throughout the article, two measures of the level of education are used. The first is the years of completed education, and the second is a discrete measure based on the highest level of education completed. To create the second measure, years of completed education are divided into four groups: high school dropouts, high school graduates, those with some college, and college graduates (with a four-year degree or higher). Figure 1 presents years of completed education over time and by generation for individuals ages 30 to 35 .

Panels A to E of Figure 1 present the years of completed education over time by gender, marital status, and race. Panel A shows the well-documented reversal in the gender education gap, where prior to the early 1990s, men were more educated than women; however, post 1990s, women have not only caught up to but have also overtaken men. This reversal has occurred because, while the years of completed education have significantly increased over time for both men and women, the rate of increase for women has been significantly faster.

Panels $\mathrm{B}$ and $\mathrm{C}$ of Figure 1 show that marriage is becoming more concentrated among the highly educated. This is more pronounced among women than among men. Prior to the 1990s, single men were more educated than married men; by the late 1990s, this trend had reversed. However, by 2015, single and married men had similar completed years of education. A similar pattern is observed for women prior to the early 1990s (Panel C); however, married women continued to be more educated than single women by significant margins in 2015 . It is important to note that the composition of these groups has also changed as marriage rates have fallen over the past few decades. 


\section{Figure 1}

\section{Education: Trends and Generations}
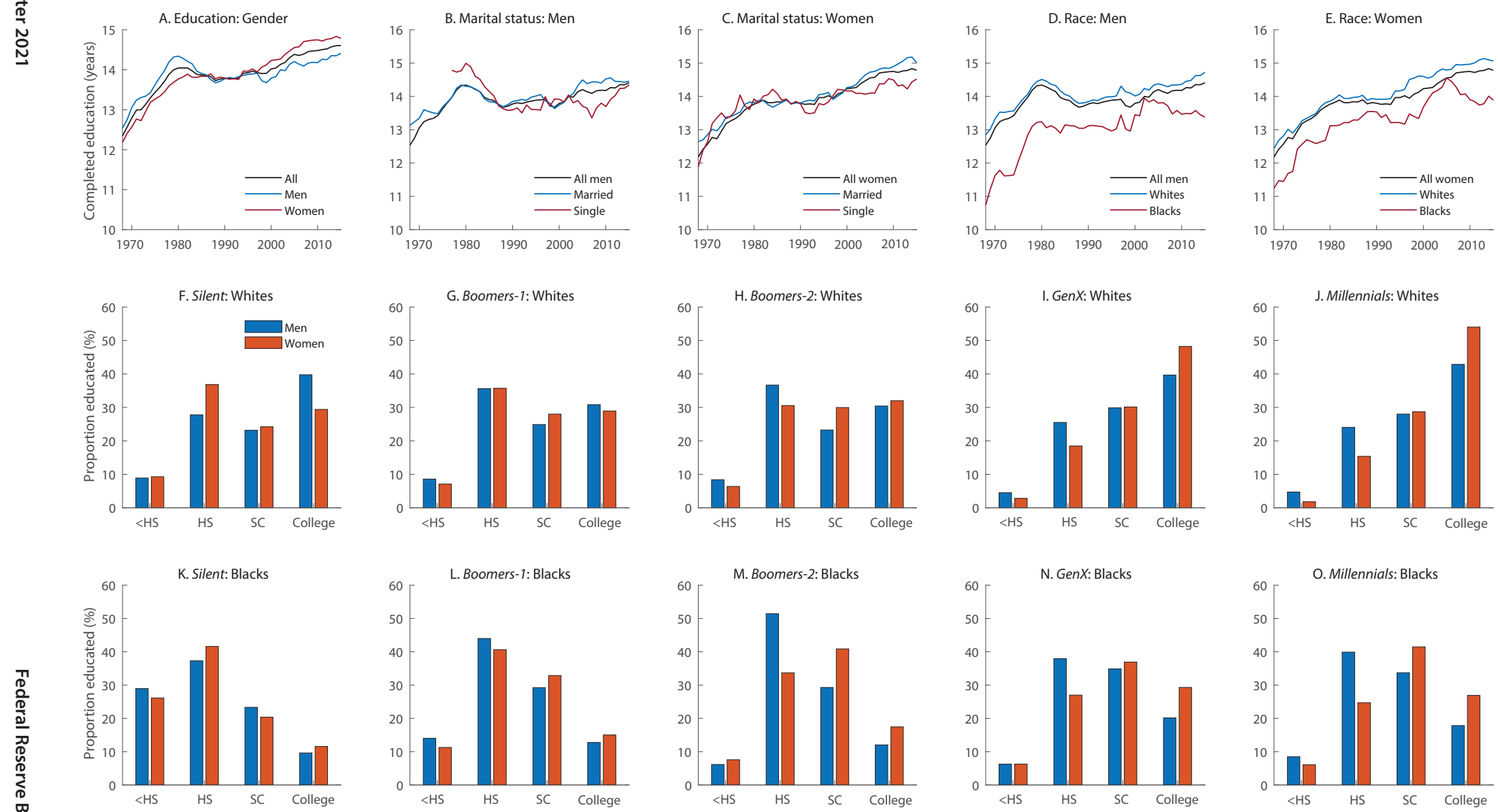

NOTE: All graphs are restricted to head and spouse. The trend graphs are restricted to ages 30 to 35 , and the relevant variable is the years of education. For the generation graphs, the unweighted proportions are plotted for ages 30 to 35 . $<\mathrm{HS}$, high school dropouts ( $<12$ years of education); HS, high school graduates ( 12 years of education); SC, those with some college ( $>12$ and $<16$ years of education); and College, college graduates (with a four-year degree or higher, 16 or more years of education).

SOURCE: PSID and authors' calculations. 
Gayle, Odio-Zuniga, Ramakrishnan

\section{Table 1}

Years of Education, by Generation

\begin{tabular}{|c|c|c|c|c|c|c|c|c|c|c|}
\hline & \multicolumn{5}{|c|}{ Men } & \multicolumn{5}{|c|}{ Women } \\
\hline & \multicolumn{5}{|c|}{ Generation } & \multicolumn{5}{|c|}{ Generation } \\
\hline & Silent & Boomers-1 & Boomers-2 & GenX & Millennials & Silent & Boomers-1 & Boomers-2 & GenX & Millennials \\
\hline Overall & $\begin{array}{c}13.42 \\
(2.76)\end{array}$ & $\begin{array}{l}13.30 \\
(2.31)\end{array}$ & $\begin{array}{l}13.10 \\
(2.81)\end{array}$ & $\begin{array}{c}13.89 \\
(2.37)\end{array}$ & $\begin{array}{c}13.91 \\
(2.35)\end{array}$ & $\begin{array}{c}13.15 \\
(2.45)\end{array}$ & $\begin{array}{l}13.30 \\
(2.38)\end{array}$ & $\begin{array}{l}13.40 \\
(2.69)\end{array}$ & $\begin{array}{c}14.28 \\
(2.32)\end{array}$ & $\begin{array}{c}14.44 \\
(2.19)\end{array}$ \\
\hline \multirow[t]{2}{*}{ Observations } & 6,981 & 11,707 & 9,143 & 8,927 & 3,608 & 6,985 & 13,306 & 11,119 & 9,872 & 4,470 \\
\hline & \multicolumn{10}{|c|}{ Marital status } \\
\hline Not married & $\begin{array}{c}13.81 \\
(2.86)\end{array}$ & $\begin{array}{l}13.01 \\
(2.31)\end{array}$ & $\begin{array}{c}12.98 \\
(2.43)\end{array}$ & $\begin{array}{c}13.47 \\
(2.23)\end{array}$ & $\begin{array}{c}13.57 \\
(2.19)\end{array}$ & $\begin{array}{c}13.06 \\
(2.38)\end{array}$ & $\begin{array}{c}13.08 \\
(2.42)\end{array}$ & $\begin{array}{c}13.15 \\
(2.71)\end{array}$ & $\begin{array}{c}13.82 \\
(2.29)\end{array}$ & $\begin{array}{c}13.99 \\
(2.20)\end{array}$ \\
\hline Observations & 618 & 2,247 & 2,268 & 2,501 & 1,380 & 1,077 & 3,083 & 3,218 & 3,250 & 1,823 \\
\hline Married & $\begin{array}{c}13.69 \\
(2.49)\end{array}$ & $\begin{array}{c}13.01 \\
(2.31)\end{array}$ & $\begin{array}{c}13.17 \\
(2.91)\end{array}$ & $\begin{array}{c}14.14 \\
(2.34)\end{array}$ & $\begin{array}{c}14.22 \\
(2.38)\end{array}$ & $\begin{array}{c}13.42 \\
(2.31)\end{array}$ & $\begin{array}{c}13.08 \\
(2.42)\end{array}$ & $\begin{array}{c}13.52 \\
(2.68)\end{array}$ & $\begin{array}{c}14.55 \\
(2.26)\end{array}$ & $\begin{array}{c}14.81 \\
(2.05)\end{array}$ \\
\hline \multirow[t]{2}{*}{ Observations } & 5,200 & 2,247 & 6,676 & 6,107 & 2,105 & 5,022 & 3,083 & 7,780 & 6,471 & 2,545 \\
\hline & \multicolumn{10}{|c|}{ Race } \\
\hline Whites & $\begin{array}{c}13.99 \\
(2.61)\end{array}$ & $\begin{array}{l}13.66 \\
(2.32)\end{array}$ & $\begin{array}{l}13.45 \\
(2.77)\end{array}$ & $\begin{array}{c}14.21 \\
(2.24)\end{array}$ & $\begin{array}{l}14.37 \\
(2.27)\end{array}$ & $\begin{array}{c}13.58 \\
(2.36)\end{array}$ & $\begin{array}{c}13.59 \\
(2.42)\end{array}$ & $\begin{array}{c}13.66 \\
(2.71)\end{array}$ & $\begin{array}{c}14.67 \\
(2.15)\end{array}$ & $\begin{array}{c}14.94 \\
(1.96)\end{array}$ \\
\hline Observations & 4,912 & 7,262 & 5,860 & 5,701 & 2,100 & 4,618 & 7,712 & 6,379 & 5,582 & 2,379 \\
\hline Blacks & $\begin{array}{c}12.10 \\
(2.51)\end{array}$ & $\begin{array}{c}12.85 \\
(1.87)\end{array}$ & $\begin{array}{c}12.85 \\
(2.12)\end{array}$ & $\begin{array}{c}13.37 \\
(2.26)\end{array}$ & $\begin{array}{c}13.29 \\
(1.87)\end{array}$ & $\begin{array}{c}12.29 \\
(2.34)\end{array}$ & $\begin{array}{l}13.07 \\
(2.00)\end{array}$ & $\begin{array}{c}13.42 \\
(2.03)\end{array}$ & $\begin{array}{c}13.91 \\
(2.23)\end{array}$ & $\begin{array}{c}13.82 \\
(2.30)\end{array}$ \\
\hline Observations & 1,942 & 4,025 & 2,432 & 2,507 & 1,216 & 2,204 & 5,107 & 3,800 & 3,572 & 1,731 \\
\hline
\end{tabular}

NOTE: The data are calculated for ages 30 to 35 . Marital status is defined as the marital status at the time of the observation.

SOURCE: PSID and authors' calculations.

Panels D and E of Figure 1 show that the significant convergence of the racial education gap stalled and since the early 2000s has reversed. As shown in Panel D, the racial education gap between Black men and White men trended toward convergence; however, post 2004, the trend reversed and started diverging. A similar trend is seen for Black women and White women as well (Panel E); however, the divergence occurs at a much later point in timepost 2007.

Table 1 presents the years of completed education by gender, marital status, and race over generations. $\underline{7}$ The table pins down the reversal of the gender education gap: It occurred with the Boomers-2 generation, where men have only 13.10 years of education compared with 13.40 years for women. For the Millennials generation, the levels have increased for men and women but the gap persists (13.91 years for men versus 14.44 years for women). Similar to Figure 1, Table 1 also shows reversals in the education gaps by marital status-for both men and women in the Boomers-2 generation. However, the convergence for men is not seen. Interestingly, the racial gap in years of education follows a similar trend for both men and women: It narrows until the Boomers-2 generation and then starts widening again. 


\section{Gayle, Odio-Zuniga, Ramakrishnan}

Focusing on years of education only tells half the story. The transition between education groups also needs to be understood. There is certainly no doubt that everyone is getting more educated-but where are the gains coming from? Is it from a rise in the college graduates category or some other category? Panels $\mathrm{F}$ to $\mathrm{O}$ of Figure 1 present the discrete measures of completed education by gender and race. For the Silent and Boomers-1 generations, White men had much higher rates of college completion (college graduates category) than White women; however, the reversal started with the Boomers- 2 generation and has increased by a significant margin for the Millennials generation. Namely, 43 percent of Millennial men and 54 percent of Millennial women are college graduates compared with 40 percent and 29 percent of the Silent generation, respectively. The similarities between GenX and Millennials in terms of the proportions educated in each age group is striking, with Millennials being more educated, as a higher proportion are college graduates.

While there has not been much progress at the top of the education distribution for Blacks, there has been some progress for them at the bottom of the distribution, with a fall in high school dropouts from the Silent to the Boomers-2 generation (Panels K to O of Figure 1). For example, 29 percent and 26 percent of Black men and Black women, respectively, of the Silent generation were high school dropouts, but those numbers fell to 8.5 percent and 6.0 percent, respectively, for Black Millennials. The college graduation rate for Blacks rose significantly from the Silent generation to GenX; however, for Black Millennials, the college graduation rate has fallen.

Most articles in the literature tend to focus on the stock of educated individuals, that is, years of education for individuals ages 25 to 64, for example, Blau and Kahn (2017). While these numbers are not directly comparable to our numbers, the same trends are seen for the reversal of the gender gap. As documented by Goldin, Katz, and Kuziemko (2006), there has been a sharp rise in college graduation rates for women as well as a slower rise for men. They suggest that one of the reasons for this rise for women is changing social norms and expectations about work, marriage, and motherhood. Similar to Murnane (2013), we find that Blacks are less likely to graduate from college, while women are more likely to. Eckstein, Keane, and Lifshitz (2019) also document the reversal in the trend of education of married women versus single women. They find that while in 1962 only 7 percent of married women and 10 percent of unmarried women had a bachelor's degree or higher, by 2015 this pattern had reversed: 36 percent of married women but only 28 percent of unmarried women had a college degree (or higher). This finding is consistent with the trend shown here.

\subsection{Employment and Annual Hours Worked}

In this section, the employment rate is defined as the fraction of the total working-age population employed. The working-age population refers to individuals ages 18 to 65 , and an individual is classified as employed if they work a positive number of hours during the calendar year.

Figure 2 presents the patterns of the employment rate for the sample from 1968 to 2015 for different demographic groups and the life-cycle profiles across generations. Panel A of Figure 2 shows that although the employment rate for women increased from 1968 to 2015, the rate of increase slowed considerably from 2000 to 2015. At the same time, the employment 


\section{Figure 2}

\section{The Employment Rate: Trends and Generations}
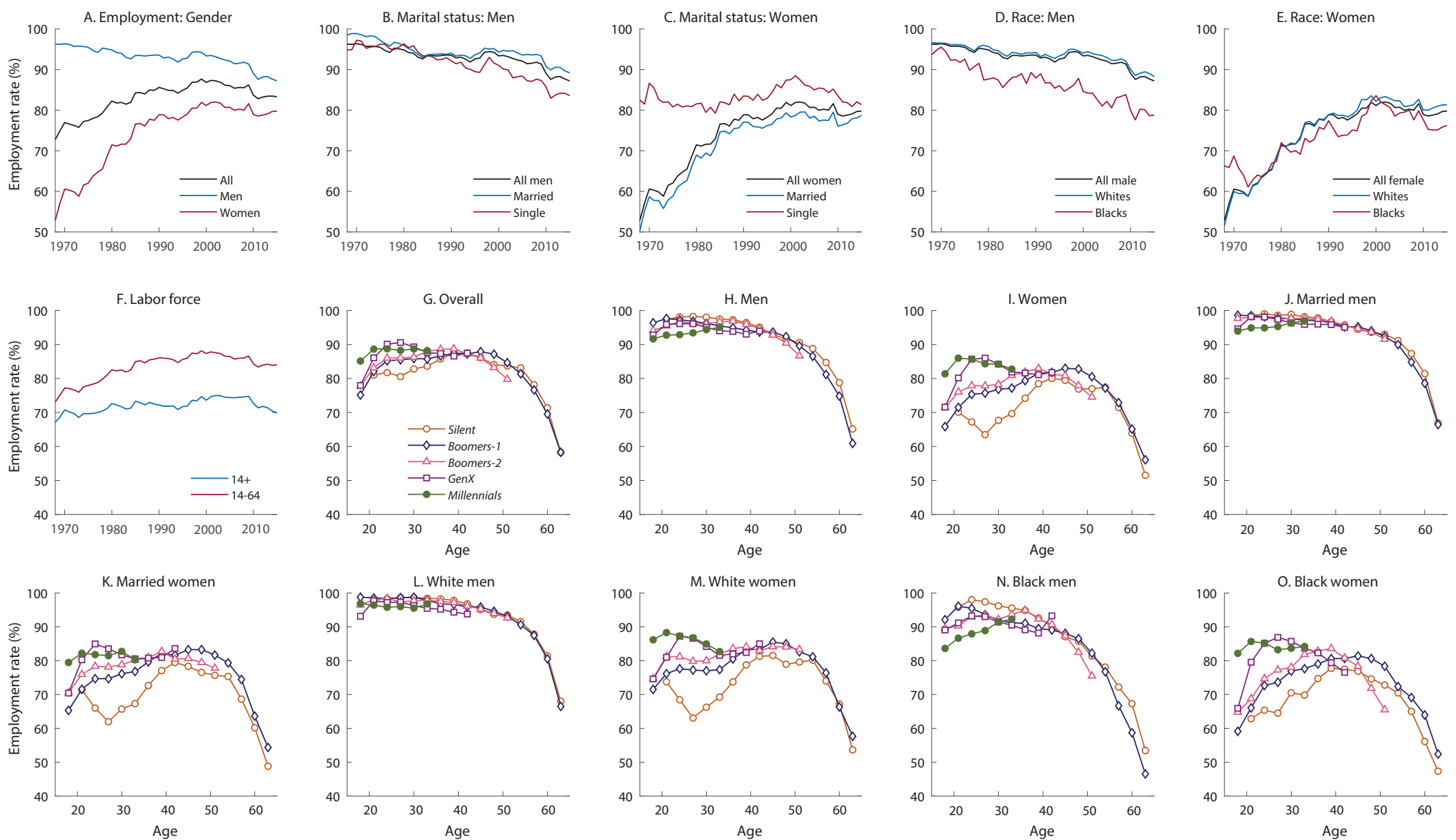

NOTE: An individual is classified as employed if a positive number of hours are spent working and as unemployed if zero hours are worked. All graphs are restricted to head and spouse of the family unit. The trend graphs are restricted to ages 18 to 65 . The generation graphs are also restricted to ages 18 to 65 and are plotted for three age-group intervals for smoothing of the trend. For example, age 18 refers to the 18-20 age group.

SOURCE: PSID and authors' calculations. 


\section{Gayle, Odio-Zuniga, Ramakrishnan}

rate for men decreased from 1968 to 1993, with a slight recovery thereafter. The employment rate decreased during the Great Recession for both genders; however, the fall was greater for men than for women. For example, the employment rates in 2008 were 92 percent and 80 percent for men and women, respectively; in 2010, they dropped to 89 percent and 79 percent, respectively; and by 2015 they were 87 percent and 80 percent, respectively.

After controlling for marital status, the employment gap between married and single men $\underline{8}$ widened after 1990, while the employment gap between married and single women shrank but persisted throughout the whole period (Panels B and C of Figure 2, respectively). On the other hand, the employment rates for Black men fell more sharply than those for White men and the racial employment gap between them has continued to widen (Panel D). In the early 1980s, Black women had higher employment rates than White women. The gap was the smallest in the early 2000s, but by 2008, the recession affected Black women more, spreading the gap again (Panel E).

Panels $\mathrm{G}$ to $\mathrm{O}$ of Figure 2 analyze employment rates using the life-cycle profiles over generations. The increases in employment rates by generation are shown in Panel G, with GenX and Millennials having fairly similar rates. Separating the trends by gender shows that the rises in the overall employment rates have primarily come from women (Panel I) and that men's employment rates have steadily declined (Panel H), with Millennial men working the least of all generations. In contrast, Millennial women have higher employment rates than all other generations of women except GenX. For women ages 30 to 32, the employment rate rose from 67.6 percent for the Silent generation to 84.2 percent for Millennials; for men of the same ages, it fell from 98.0 percent to 94.4 percent. These patterns for men and women are robust; they persist even after conditioning on marital status and race (Panels $J$ to $\mathrm{O}$ ). The shape of the age profile for women flattens from the Silent generation to Millennials. This is possibly due to changes in patterns of fertility, which are analyzed in Section 5.1. 9

Other articles tend to use different definitions of the employment rate and working-age population for two reasons: (i) the legal working age has changed over time and (ii) data sources differ. For example, Ramey and Francis (2009) use data from the U.S. Census and the Bureau of Labor Statistics to calculate the employment rate using the same definition as in this article. However, they provide three age measures for the working-age population: (i) age 10 and older, (ii) age 14 and older (14+), and (iii) ages 14 to 64 . They report that for the period 1900-2005, the employment rate rose from 51 percent to 60 percent for measure (i), from 55 percent to 64 percent for measure (ii), and from 56 percent to 73 percent for measure (iii). For comparability, using the PSID dataset, the employment rate is constructed for ages $14+$ and ages 14 to 64 (Panel F of Figure 2). 10 The pattern found by Ramey and Francis (2009) is confirmed. In addition, the time series is extended until 2015 and the increasing trend continues until 2009. Due to the impact of the recession, the rate fell from 75 percent in 2009 to 70 percent in 2015 for working ages 14+ and from 87 percent to 84 percent over the same period for working ages 14 to 64. Similarly, Blau and Kahn (2017) find that the employment rates for women increased from 1947 to 2013 and that the gender gap has narrowed due to a steady decline in employment rates for men over this period. $\underline{11}$ In Panel A of Figure 2, the same trend is seen for men and women; however, the findings of this article have higher employment 


\section{Figure 3}

\section{Annual Hours Worked: Trends and Generations}
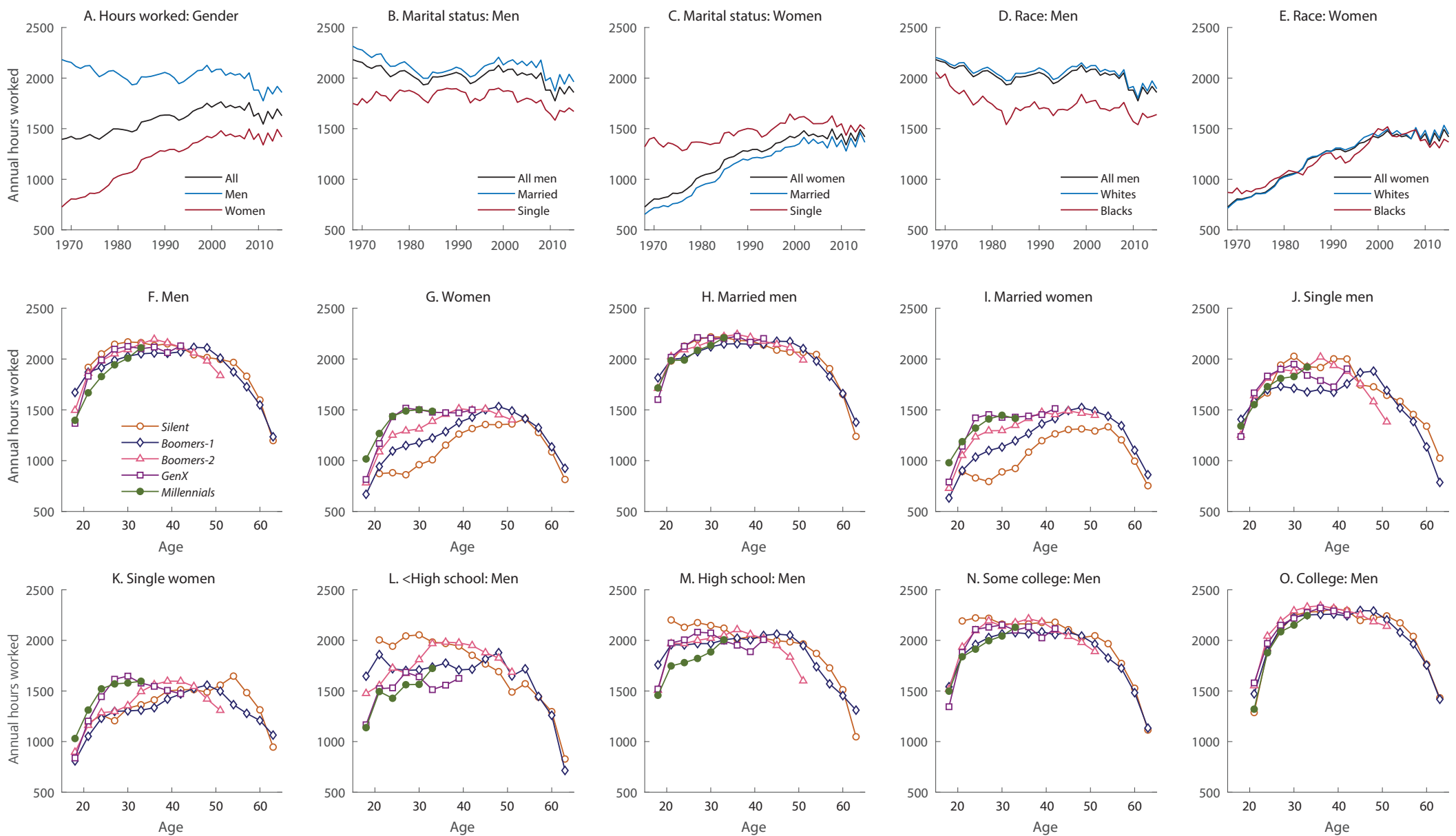

NOTE: All graphs are restricted to head and spouse. The trend graphs are restricted to ages 18 to 65 . The generation graphs are also restricted to ages 18 to 65 and are plotted for three age-group intervals for smoothing of the trend. For example, age 18 refers to the 18-20 age group. <High school, high school dropouts; High school, high school graduates; Some college, those with some college; and College, college graduates (with a four-year degree or higher).

SOURCE: PSID and authors' calculations. 


\section{Gayle, Odio-Zuniga, Ramakrishnan}

rates than those presented by Blau and Kahn (2017). 12 Greenwood (2019) also finds that over time, women's labor supply has risen and suggests this may be from a decline in the amount of time women spend on housework, a topic discussed in detail in Section 4.1.

Figure 3 presents the trends and life-cycle profiles for annual hours worked for different demographic groups, which are taken directly from survey data. The results show that annual hours worked mirror the trends of employment rates over time and across generations. The one exception is the racial gap for women, which is non-existent in this case. The long-run trends presented in Figure 3 are supported by the findings of Aguiar and Hurst (2007). They find that hours worked in the labor market decreased significantly for men but increased for women over the period 1965-2003. However, they also find that the average time men and women spent on total market work dropped from 35.9 hours per week to 31.7 hours per week over the period 1965-2003, despite women increasing their time in market work. $\underline{13}$

\subsection{Wages}

In this article, wages are calculated in hourly terms, with the total labor income of an individual divided by the total annual hours worked and then deflated to 2015 U.S. dollars values. $\underline{14}$

Any discussion about wages has to begin with the wage gap. Panel A of Figure 4 shows there has been convergence in men's and women's median hourly wages, with the women-tomen median-wage ratio increasing from 59 percent to 83 percent-inching closer to parity. Although wages have been stagnant for men and women college graduates (Panels B and C, respectively), there has been a clear decline in the wages of all other education groups for men. This decline has resulted in a polarization of wages across education groups. For women, wages have stagnated for all education groups. This finding would imply that the college premium has risen more for men than women. Regarding racial wage gaps (Panel D), the Blackto-White wage ratio has declined for men, whereas for women the 2015 level is similar to the 1968 level.

Panel E of Figure 4 disaggregates the trends by worker type and shows convergence in the women-to-men hourly wage ratio both for all workers and for full-time workers. This finding implies that this ratio for part-time workers is catching up with that of full-time workers. The same exercise for annual earnings shows a similar convergence trend; however, the initial gaps in earnings in 1968 are close to 61 percent for all workers and 45 percent for full-time workers-these fall to 33 percent and 25 percent, respectively, by 2015 (Panel F). The convergence in the annual earnings of men and women is a function of hours worked as well, and as stated earlier, there has been a sharp rise in the hours worked by women and a marginal decline for men.

Real hourly wages for men by generation show a sharp fall from the Silent to the Boomers-2 generation (Panel G). Although there was a rise in real wages over the life cycle for GenX relative to previous generations, these gains have not been seen by Millennials-who have the lowest real wages over the life cycle so far. Specifically, real hourly wages for men ages 30 to 32 were $\$ 23.50$ for the Silent generation but have fallen to $\$ 17.80$ for Millennials. A flattening of the wage-age profiles over the generations is also seen, confirming the trend documented 


\section{Figure 4}

\section{Wages: Trends and Generations}
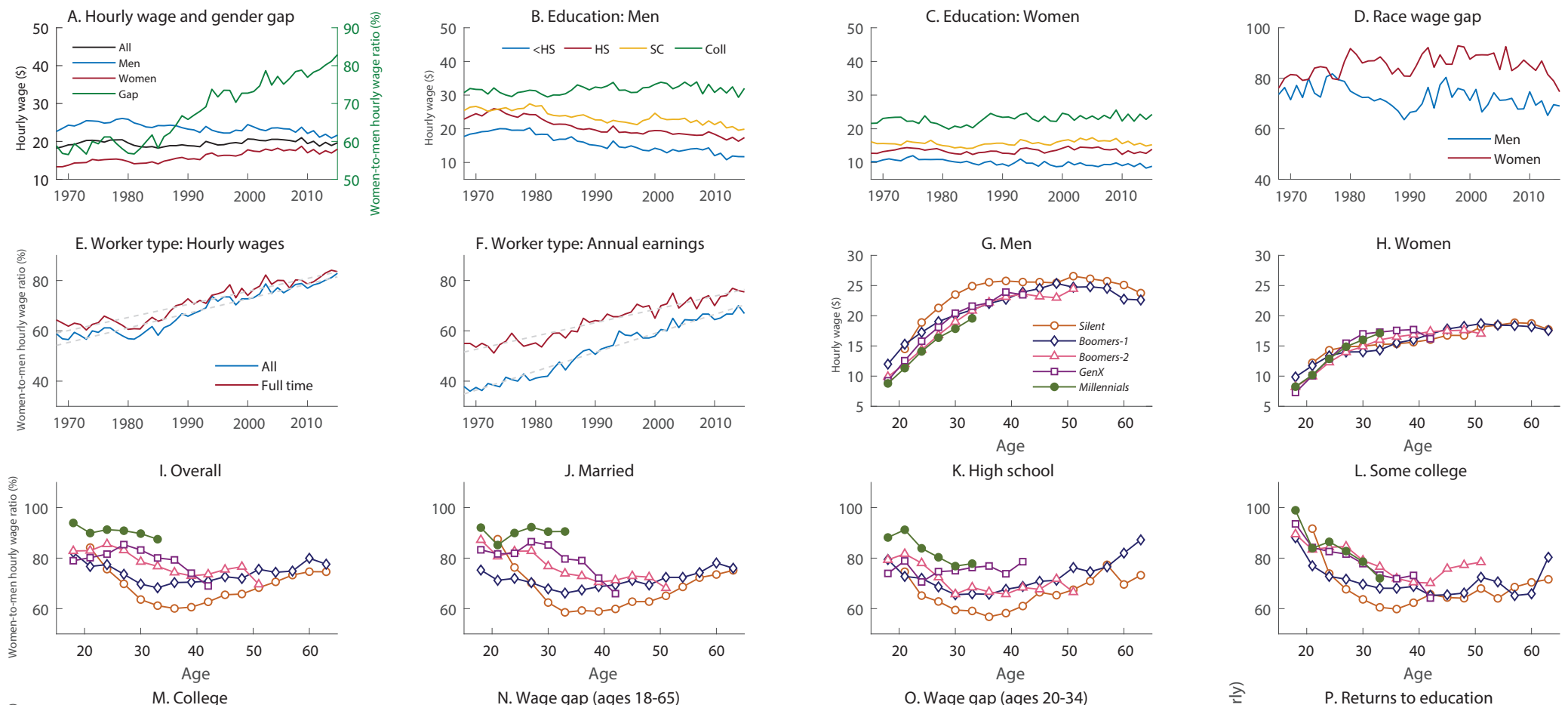

J. Married
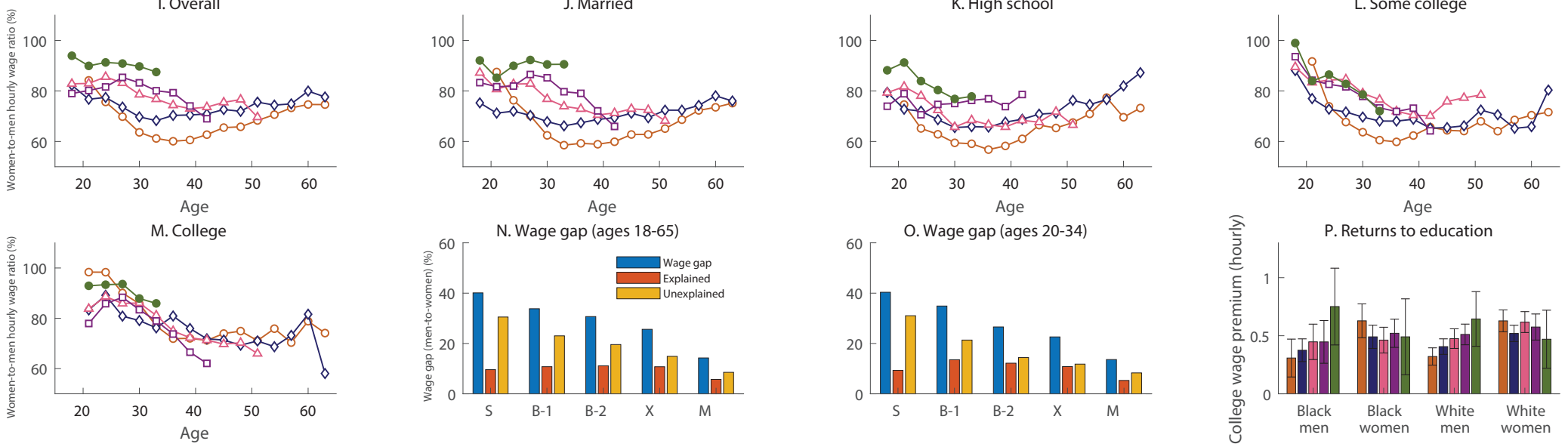

NOTE: All of the graphs are restricted to head and spouse. The trend graphs are restricted to ages 18 to 65 . Graphs $\mathrm{E}$ and $\mathrm{F}$ also present a fitted time trend. Panel P represents the college wage premium as presented in Chiappori, Salanié, and Weiss (2017) but with different definitions of generations. See the main text for more details. The wages used in

Panels $\mathrm{N}$ and $\mathrm{O}$ are log wages and truncated at the bottom 1 and top 99 percentiles. The bar colors on Panel P correspond to the colors/labels on Panel G. The generation graphs are also restricted to ages 18 to 65 and are plotted for three age-group intervals for smoothing of the trend. For example, age 18 refers to the 18-20 age group. <HS, high school dropouts; High school (HS), high school graduates; Some college (SC), those with some college; and College (Coll), college graduates (with a four-year degree or higher). S, Silent generation; B-1, Boomers-1; B-2, Boomers-2; X, GenX; and M, Millennials.

SOURCE: PSID and authors' calculations. 


\section{Gayle, Odio-Zuniga, Ramakrishnan}

by Kong, Ravikumar, and Vandenbroucke (2018). It does appear as though men are being left behind, with the stagnation of men's education as well as a fall in hours worked. Interestingly, this trend is not seen for women. The rise in women's wages over previous generations begins with GenX and is carried forward by Millennials, although it is not as high for Millennials after age 27 (Panel H). However, in levels, men's wages are still higher than women's (Panels G and H).

The median women-to-men wage gaps clearly show that Millennials have made the largest strides toward gender equality in pay (Panels $\mathrm{N}$ and $\mathrm{O}$ ). Moreover, there has been a change in the profiles over the life cycle as well: Earlier they had an inverted- $U$ shape, but the profiles over the life cycle have become much flatter in the recent generations. The trend is similar across married and unmarried individuals. Splitting the wage gap by education group shows that it is much smaller for college graduates than high school graduates or those with only some college (Panels K to M).

Framework for Analyzing Wages. Following the human capital accumulation literature (Altuğ and Miller, 1998; Gayle and Miller, 2006; Gayle and Golan, 2012; and Chiappori, Salanié and Weiss, 2017), the following specification is used to analyze wages:

$$
\log \left(w_{i t}\right)=\sum_{r=1}^{4} \gamma_{1}^{r} d_{i, t-r}+\sum_{r=1}^{4} \gamma_{2}^{r} h_{i, t-r}+\gamma_{3} a_{i t}+\gamma_{4} a_{i t}^{2}+\eta_{i}+\epsilon_{i t},
$$

where $w_{i t}$ denotes the hourly wages of individual $i$ in calendar year $t$. The return to experience is captured by two components: $d_{i, t-r}$, the indicator for labor force employment of individual $i$ in calendar year $t-r$, and $h_{i, t-r}$, the hours worked by individual $i$ in calendar year $t-r$. The standard age-earnings profile is captured by age, denoted by $a_{i t}$, and age squared. Generically, an individual-specific effect is included and denoted by $\eta_{i} \cdot \underline{15}$

Decomposition of Wage Gaps. As in Blau and Kahn (2017), the framework in (1) is used to perform an Oaxaca-Blinder decomposition of the different wage gaps into an unexplained and an explained component. This estimation of (1) is done separately by gender, race, and generation. The coefficient on the hours worked is restricted to be the same across $t-r$; that is, $\gamma_{2}^{r}=\gamma_{2} \forall r=\{1,2,3,4\}$. The individual-specific component is specified as a linear function of completed education. Completed education is discretized into four categories: high school dropouts, high school graduates, those with some college, and college graduates.

Panel $\mathrm{N}$ of Figure 4 shows that there has been a significant decline across generations in the women-to-men mean wage gap $\frac{16}{}$ for those ages 18 to 65 (where the data for a specific age group are available). However, since all age groups are not available for all generations, Panel $\mathrm{O}$ is restricted to ages 20 to 34 for direct comparison and shows the same sharp decline. Ages 18 to 65 have a sharp fall in the unexplained component of the wage gap over the generations, from 30.5 percent for the Silent generation to 8.5 percent for Millennials. However, the proportion in the total wage gap accounted for by the unexplained component has also fallen from 76 percent for the Silent generation to 60 percent for Millennials. Because education and hours worked have risen over generations, this finding makes intuitive sense because experience and education are the variables most predictive of the wage level. However, there appears to be a marginal rise in the explained component for GenX, which then falls for Millennials. A similar trend is observed for ages 20 to 34; the explained component appears to rise for 
Boomers-1 relative to the Silent generation and then starts to fall. For GenX, 48 percent of the wage gap is accounted for by the explained component, which falls to 39 percent for Millennials.

Returns to Education. Has the return to education changed over generations? To answer this question, a decomposition exercise is performed and is similar to the one in Chiappori, Salanié, and Weiss (2017). First, equation (1) is estimated by gender, education, race, and generation. In this regression, the individual-specific component is unrestricted as a fixed effect. For comparability with the results presented in Chiappori, Salanié, and Weiss (2017), it is assumed that $h_{i, t-r}$ represents the proportion of total time endowment $\frac{17}{17}$ hours worked by individual $i$ in calendar year $t-r$, instead of the actual amount of hours worked. The returns to education are calculated by subtracting the predicted log wage of a college graduate from that of a high school graduate. The college wage premia presented in Panel P of Figure 4 are for an individual who is age 35 and has worked full-time in the past four periods $((40 \times 52) /$ $(365.25 \times 24))$.

As Panel P shows, labor market college premia have increased for men (both Black and White) over generations. On the other hand, the trend for women has not been that straightforward. For Black women, it fell from the Silent to the Boomers-2 generation and then rose (representing a U shape) for GenX. For White women, it fell for Boomers-1, increased for Boomers-2, and then continued to fall for the subsequent generations. It is important to note that the differences in these numbers are not statistically significant from zero. A similar fall was reported in Chiappori, Salanié, and Weiss (2017); however, the recent rise in the labor market premia for Black women has not been documented before.

\section{LEISURE}

\subsection{Housework Hours}

There has been much talk about technological progress helping in the reduction of time spent on housework (Greenwood and Seshadri, 2005). Figure 5 presents the trends for annual housework hours over the years and by generation. Housework hours are calculated on an annual basis by multiplying weekly housework hours (as reported by the PSID) by 52 . The PSID does not report weekly housework hours in the years 1975 and 1982 and does not ask this question in the T-2 years. Figure 5 shows some very striking trends. Over the years, men have increased their housework hours, while women have drastically reduced theirs. On an overall level, housework hours have declined, implying that the fall in these hours for women has not been offset by the rise in these hours for men (Panel A of Figure 5). However, no conclusions can be drawn from simply focusing on the hours, as there might have been significant technological progress in home production $\frac{18}{}$ and, therefore, equal time spent in 1968 and 2015 would produce different levels of output.

Before the 1990s, married men did not spend as much time on housework as single men (not shown on Figure 5); after that, the trend has been similar by marital status. However, single women spend significantly less time on housework than married women (and always have). Most of the decline in housework hours appears to come from married women, who 


\section{Figure 5}

Annual Housework Hours: Trends and Generations
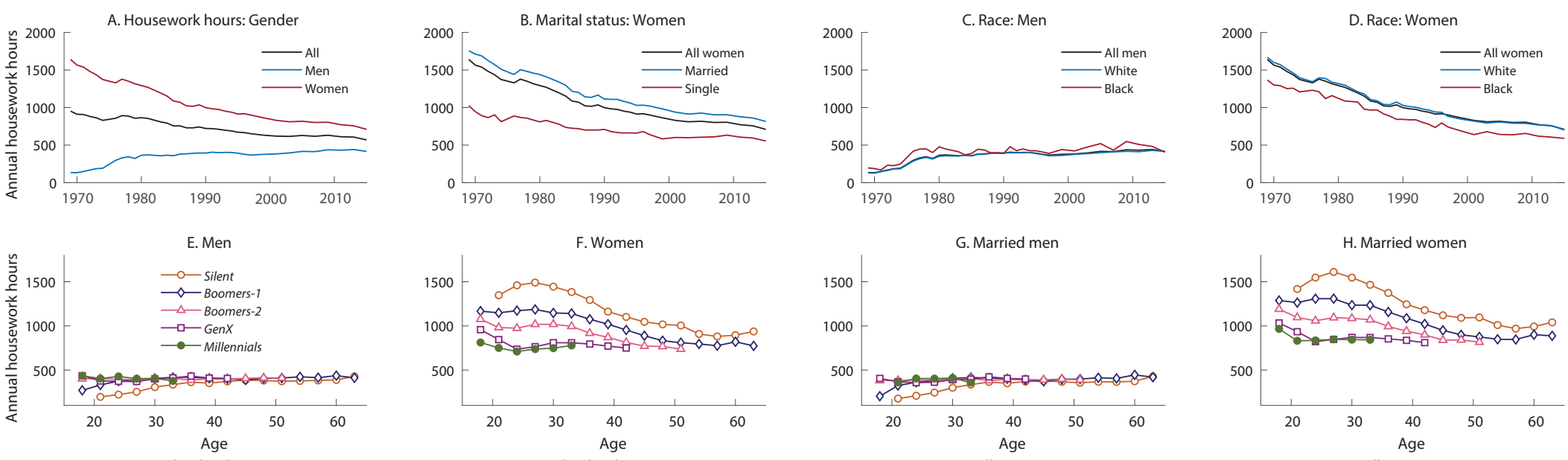

F. Women

G. Married men
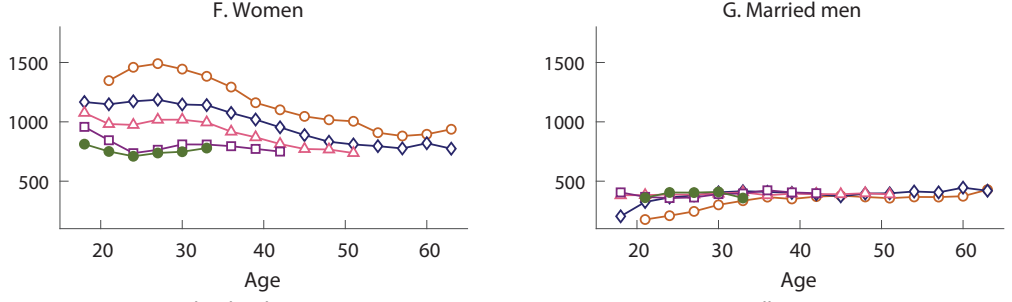

H. Married women

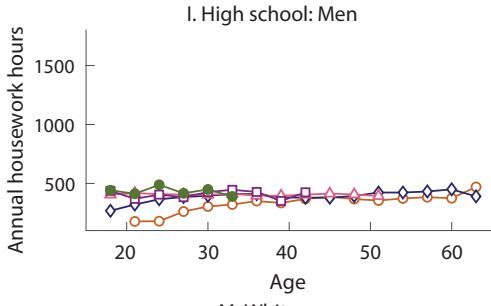

J. High school: Women

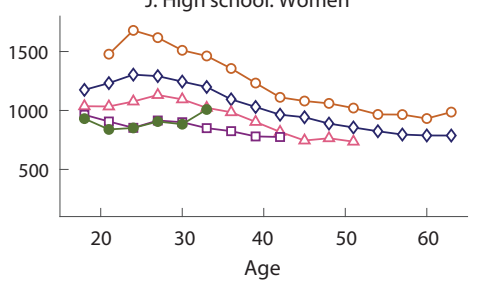

K. College: Men
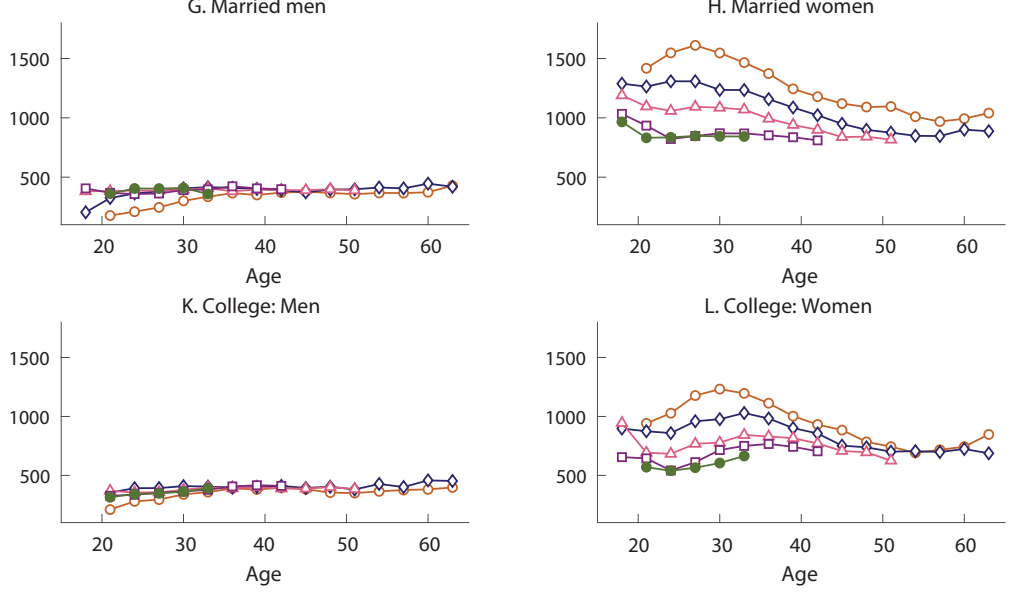

N. White wom
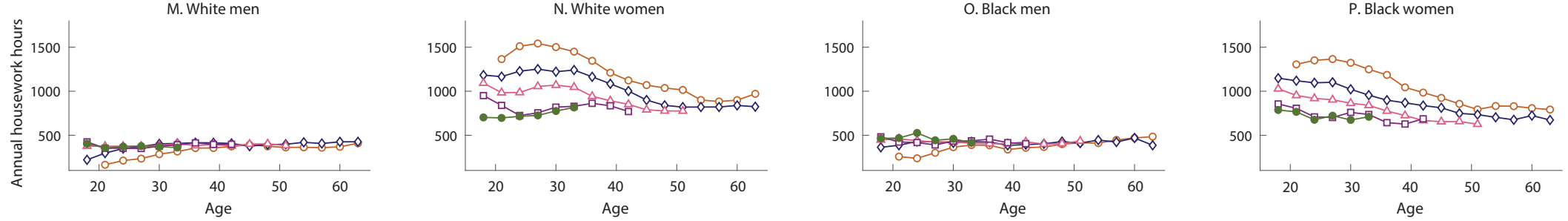

NOTE: All graphs are restricted to head and spouse. The trend graphs are restricted to ages 18 to 65 . Annual housework hours are calculated by taking the weekly housework hours, as reported by the PSID, and multiplying by 52. The generation graphs are also restricted to ages 18 to 65 and are plotted for three age-group intervals for smoothing of the trend. For example, age 18 refers to the 18-20 age group. High school, high school graduates, and College, college graduates (with a four-year degree or higher).

SOURCE: PSID and authors' calculations. 
saw a drastic fall from 1,641 hours in 1968 to 709 hours in 2015 (Panel B of Figure 5). Married women have also increased their labor supply. One argument put forward in the literature that would be consistent with this observation would be a significant improvement in household technology. Since technology costs more, women might need to increase their labor supply to be able to afford it. However, technology might also reduce the time women spend on housework (Greenwood, 2019).

There is not much difference in housework hours by race for men (Panel C), while Black women put in fewer housework hours than White women (Panel D). It is important to note that Black married women spend more hours working in the labor market than White married women; however, since there are more Black single women in our data set, the aggregated trend of Black women is more representative of the single ones.

Examining the data by generation paints an even clearer picture about the change in housework hours. While Millennial men do spend more hours on housework than the previous generations of men, the rise over the generations has not been that dramatic (Panel E). On the other hand, there is a clear fall with each generation for women (Panels F); and as seen earlier, most of this fall comes from married women. When looking at disaggregation by education, it is important to note that across all generations, housework hours decrease as educational attainment increases: Women college graduates put in the least number of hours relative to the other education groups. Of Millennial women ages 30 to 32, the high school graduates spent 883 hours on housework (Panel J), while the college graduates spent 605 hours (Panel L). However, this trend is not seen for the men (Panels I and K). The same patterns for race are seen as in the time-trend panels.

The findings of this article on the fall in the housework hours for women and rise of them for men is confirmed by Ramey and Francis (2009) and Aguiar and Hurst (2007). Both of those articles use different datasets from the PSID. Ramey and Francis (2009) compute housework hours using data from the American Heritage Time Use Survey and American Time Use Survey of the Bureau of Labor Statistics, $\underline{19}$ while Aguiar and Hurst (2007) link five major time-use surveys $\underline{\underline{20}}$ to get their results. $\underline{21}$ Thus, the trends of rising housework hours for men and falling hours for women appear to be robust to the source of data and method of measurement.

Framework for Analyzing Housework Hours. In the previous section, aggregate housework hours were examined over time and by generation; however, it is important to understand what predicts housework hours at the individual level in order to understand the driving force behind these changes. Is it education, marital status, or the number of children? There have been changes over time and generations in education, family structure, and the number of children. These variables are known to be correlated with the number of hours spent on housework. Can they statistically explain the change in housework hours over generations? To answer this question, a statistical decomposition exercise is conducted using the following regression for Blacks and Whites together: 


$$
h_{i t}^{w}=\alpha_{0}+\sum_{r=2}^{5} \alpha_{1, r} g_{i, r}+\beta \mathbf{Z}_{\mathbf{i t}}+\sum_{r=2}^{5} \delta_{r} g_{i, r} \mathbf{Z}_{\mathbf{i t}}+\epsilon_{i t},
$$

where $h_{i, t}^{w}$ denotes annual housework hours for individual $i$ in calendar year $t$ and $g_{i, r}$ is an indicator equal to 1 if individual $i$ is from generation $r$ and zero otherwise. In this specification, the Silent generation is set as the baseline $(r=1)$. The regression includes controls for education, gender, race, marital status, the number of young children (less than age 6), the number of old children (ages 6 to 18), age, and age squared. These are all represented in equation (2) by the vector $\mathbf{Z}_{\mathrm{it}}$, whose effects are allowed to vary across generations.

What Explains Housework Hours? Two possible explanations are explored in this analysis of housework hours: the roles of education and children. To isolate the effects of these separately, the following approach is used. First, using the regression model in equation (2), the effect of education is isolated by focusing on a baseline case of an age 35 high school dropout with no children and analyzing the change in housework hours as educational attainment is increased. Figure 6 presents the predicted housework hours by education group. Second, two additional specifications of the regression model in equation (2) are estimated by imposing restrictions on the interactions of children with each gender and with each generation, to disentangle the role of children. Specification (1) assumes that each of these interactions is restricted to zero. Specification (2) relaxes this restriction on the interactions between children and each generation but maintains it on the interactions between children and each gender from Specification (1). Specification (3) is the full regression, as in equation (2). Table 2 presents the regression results for young and old children for these three specifications.

As shown in Figure 6, the most striking features of the role of education are the increase in housework hours for men over generations and the even larger decline in housework hours for women over generations for the baseline case. As educational attainment increases, the housework hours for women decline, thus indicating that part of the reason for the large decline over generations is the significant increase in the educational attainment of women over generations. However, educational attainment has a marginal effect on the increase in housework hours for men over generations. Another notable feature of housework hours is that both married men and married women spend more time doing housework than single men and women.

On the other hand, examining the results from Specification (3), it is clear that young and old children have a significant impact on housework hours, with young children having a higher impact than old children. Compared with the Silent generation, each generation spends less time in housework when young children are in the household. However, for households with old children, the Silent generation and Boomers-1 spend the same amount of time in housework, with a fall in housework hours for each successive generation.

After controlling for children, the estimated coefficients on the generation dummies are all positive and statistically significant. Additionally, more children are associated with a large increase in housework hours for women. This finding implies that a large part of the decline in women's housework hours over generations is explained by the significant decline in the number of children. However, there is a possible role for home production technological 
Table 2

The Effects of Young and Old Children on Housework Hours, by Gender and Generation

\begin{tabular}{|c|c|c|c|}
\hline & (1) & $(2)$ & (3) \\
\hline Women & $\begin{array}{c}1,097.031^{* * *} \\
(9.9872)\end{array}$ & $\begin{array}{c}1,098.919^{* * *} \\
(10.0121)\end{array}$ & $\begin{array}{c}860.877^{* * * *} \\
(10.2262)\end{array}$ \\
\hline Young children & $\begin{array}{c}101.702^{* * * *} \\
(1.6538)\end{array}$ & $\begin{array}{c}111.478^{* * *} \\
(3.8219)\end{array}$ & $\begin{array}{c}25.210^{* * *} \\
(3.3746)\end{array}$ \\
\hline Old children & $\begin{array}{c}67.786^{* * *} \\
(1.2849)\end{array}$ & $\begin{array}{l}71.717 * * * \\
(2.4840)\end{array}$ & $\begin{array}{l}8.636^{* * *} \\
(2.3159)\end{array}$ \\
\hline Women $\times$ Young children & & & $\begin{array}{c}199.714^{* * *} \\
(2.7305)\end{array}$ \\
\hline Women $\times$ Old children & & & $\begin{array}{c}118.341^{* * * *} \\
(2.2853)\end{array}$ \\
\hline Boomers-1 & $\begin{array}{l}145.832^{* * *} \\
(13.7775)\end{array}$ & $\begin{array}{l}146.919^{* * *} \\
(14.1102)\end{array}$ & $\begin{array}{l}166.766^{* * *} \\
(13.7341)\end{array}$ \\
\hline Boomers-2 & $\begin{array}{l}183.643^{* * *} \\
(16.4685)\end{array}$ & $\begin{array}{l}194.738^{* * *} \\
(16.8341)\end{array}$ & $\begin{array}{c}216.899^{* * * *} \\
(16.4876)\end{array}$ \\
\hline GenX & $\begin{array}{l}132.431^{* * *} \\
(21.3249)\end{array}$ & $\begin{array}{l}172.314^{* * * *} \\
(21.7945)\end{array}$ & $\begin{array}{l}202.435^{* * * *} \\
(21.6907)\end{array}$ \\
\hline Millennials & $\begin{array}{c}180.901^{* * *} \\
(31.5501)\end{array}$ & $\begin{array}{l}201.002^{* * *} \\
(31.6822)\end{array}$ & $\begin{array}{c}242.025^{* * *} \\
(31.7629)\end{array}$ \\
\hline Boomers- $1 \times$ Young children & & $\begin{array}{l}-2.234 \\
(4.3540)\end{array}$ & $\begin{array}{c}-15.615^{* * *} \\
(4.1247)\end{array}$ \\
\hline Boomers $-2 \times$ Young children & & $\begin{array}{l}-9.170^{*} \\
(4.7507)\end{array}$ & $\begin{array}{c}-33.499 * * * \\
(4.5933)\end{array}$ \\
\hline Gen $X \times$ Young children & & $\begin{array}{c}-36.152^{* * *} \\
(5.3375)\end{array}$ & $\begin{array}{c}-57.261^{* * *} \\
(5.2006)\end{array}$ \\
\hline Millennials $\times$ Young children & & $\begin{array}{r}-16.078^{* *} \\
(6.6208)\end{array}$ & $\begin{array}{c}-41.113^{* * *} \\
(6.4994)\end{array}$ \\
\hline Boomers- $1 \times$ Old children & & $\begin{array}{c}0.164 \\
(3.0906)\end{array}$ & $\begin{array}{l}-0.782 \\
(3.0280)\end{array}$ \\
\hline Boomers $-2 \times$ Old children & & $\begin{array}{l}-6.713^{*} \\
(3.6640)\end{array}$ & $\begin{array}{c}-14.092^{* * *} \\
(3.6290)\end{array}$ \\
\hline Gen $X \times$ Old children & & $\begin{array}{c}-17.966^{* * *} \\
(4.3959)\end{array}$ & $\begin{array}{c}-22.054^{* * *} \\
(4.3530)\end{array}$ \\
\hline Millennials $\times$ Old children & & $\begin{array}{c}-11.047 \\
(7.1474)\end{array}$ & $\begin{array}{c}-20.751^{* * *} \\
(7.0130)\end{array}$ \\
\hline Observations & 257,055 & 257,055 & 257,055 \\
\hline \multicolumn{4}{|c|}{$\begin{array}{l}\text { NOTE: Column (1) includes race; education group; gender; marital status (married or single); number of young children; } \\
\text { number of old children; age; age squared; and the interactions between gender and education group, between gender } \\
\text { and generation, between race and generation, between generation and education group, and between marriage and } \\
\text { generation. Column (2) adds the interactions between generation and young and old children. Column (3) adds the } \\
\text { interaction between gender and young and old children. }\end{array}$} \\
\hline SOURCE: PSID and authors' calculations. & & & \\
\hline
\end{tabular}


Figure 6

What Predicts Housework Hours? By Sex and Marital Status, Changing Education
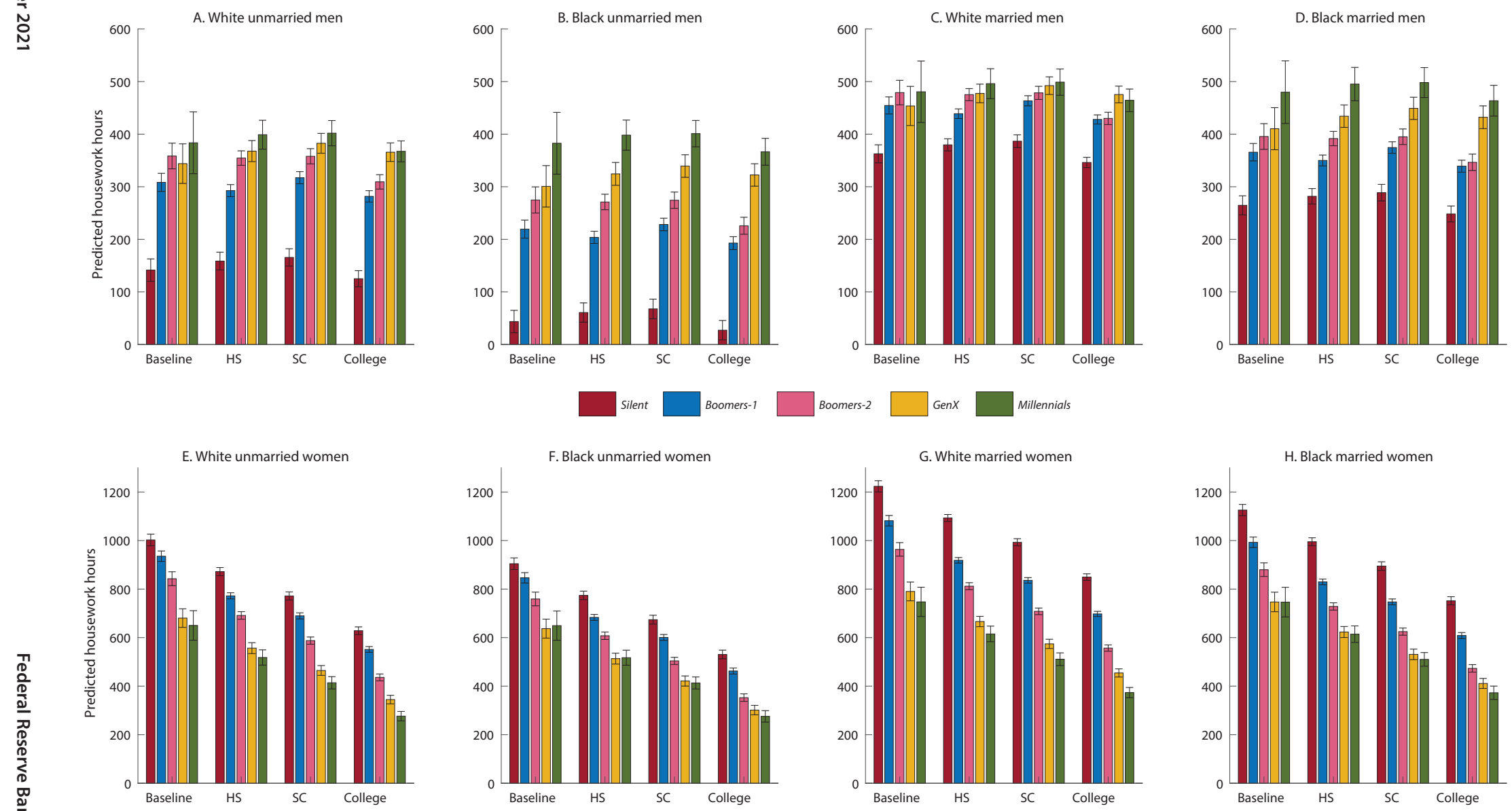

NOTE: Baseline, high school dropouts; HS, high school graduates; SC, those with some college, and College, college graduates (with a four-year degree or higher). SOURCE: PSID and authors' calculations. 
progress, as the estimated amount of housework hours needed for the number of children decreases in each subsequent generation relative to the Silent generation.

However, neither education nor children appear to contribute significantly to explaining the rise in housework hours for men. This finding implies that most of the effects are primarily cohort effects; that is, the change in household technology and gender roles result in men investing marginally more in housework hours than they used to.

\subsection{Leisure}

The small empirical literature that has studied the change in leisure hours over time and generations uses several different measures of leisure. Following Aguiar and Hurst (2007) and Aguiar, Hurst, and Karabarbounis (2012), the measure of leisure used in this study is calculated as the residual of annual hours worked and annual housework hours from total time available of 5,840 hours (where eight hours per day are allocated to sleep and personal care). $\underline{22}$ An alternative measure used in the literature (see, e.g., Ramey and Francis, 2009), defines weekly leisure as the residual time after subtracting time spent in nonleisure activities (work, school, housework, commuting, and personal care) from the time available.

Using their measure of leisure, Ramey and Francis (2009) conclude that individuals ages 25 to 54 have the lowest amount of leisure time regardless of gender. Panels A to C of Figure 7, which use the same age-group definitions as Ramey and Francis (2009), show individuals ages 25 to 54 enjoy the least amount of leisure hours, confirming the findings of Ramey and Francis (2009). This pattern holds for both genders. These panels also show that the annual leisure hours for individuals ages 25 to 54 increased between 1968 and 2015 for both genders. Aguiar and Hurst (2007) find similar patterns for the period 1965-2003. In particular, they find that leisure has increased significantly for men and women. However, using their "Leisure Measure 1" definition, which is their narrowest measure, men enjoy more leisure than women. $\underline{23}$ They also show that their result is robust to any of the four leisure measures they proposethe significant rise in leisure persisted.

Additionally, Panels D to O of Figure 7 present the life-cycle profiles for the five generations by gender, marital status, race, and education group. In general, there is a distinct $\mathrm{U}$-shaped curve across profiles, indicating that more hours for leisure are enjoyed during youth and retirement. Millennial men enjoyed higher leisure levels earlier in life than previous generations (Panel D). In contrast, for women, there was a consistent rise with each generation until GenX (Panel E). Leisure levels for Millennial women are similar to those for GenX women. Further, by marital status, married men enjoy less leisure than married women, especially, early in the life cycle (Panels F and G). For the past two generations, this is because married men have worked longer hours than married women, even though the latter have increased their market-work hours by a significant amount. For the earlier generations, housework hours dominated the effect and thus women had lower leisure. Similar patterns are found for White men and White women. Of note, the profile of Black Millennial men shifts upward with respect to the other generations, especially before age 25 . Finally, for high school graduates and college graduates, the trend of rising leisure holds for both genders (Panels L to O). 


\section{Figure 7}

\section{Annual Leisure Hours: Trends and Generations}
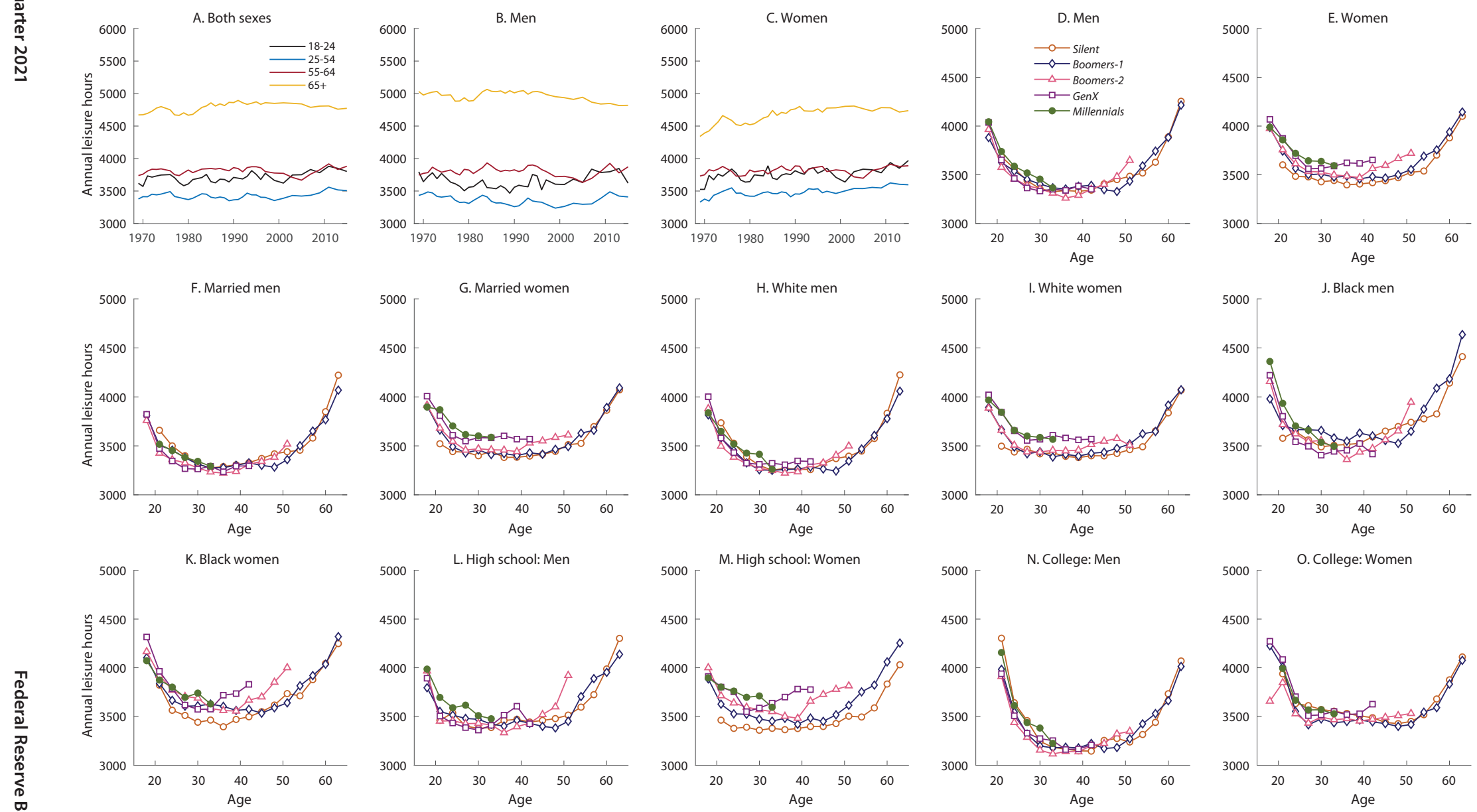

NOTE: All graphs are restricted to head and spouse. The trend graphs are restricted to ages 18 to 65 . Leisure is calculated as the difference of the sum of annual work and housework hours from total hours. The generation graphs are also restricted to ages 18 to 65 and are plotted for three age-group intervals for smoothing of the trend. For example, age 18 refers to the 18-20 age group. High school, high school graduates, and College, college graduates (with a four-year degree or higher).

SOURCE: PSID and authors' calculations. 


\section{FAMILY}

\subsection{Fertility}

A well-known fact in the academic literature is that fertility has declined over time. Panels A to C of Figure 8 present the time trends for completed fertility by marital status (if ever married), race, and education. Completed fertility corresponds to the average number of children born per woman who has reached the end of her childbearing years. Therefore, only women between ages 45 and 50 are taken into account. On average, in 1968, women had 3.04 children and by 2015 that number had decreased to 2.01 (Panel A of Figure 8). Notice the shape of the curve: There is a hump before the 1990s that then flattens out. This article does not find a big difference between women who have ever married and single women because there is little difference between "All" and "Ever-Married Women" on Panel A. Over time there has been convergence by race, although Black women have tended to have a higher average number of children than White women (Panel B). Disaggregating by education group shows a significant decline in births for women with a high school diploma or less, which may be due to a decline in teenage pregnancy. Although completed fertility for women college graduates reached a low of 1.64 in 1999, the trend has been rising since 2012, reaching a high of 1.90 in 2015 (Panel C).

A second measure used in this article to analyze fertility is the age both of men and of women when they had their first child. This is calculated by restricting the sample to individuals ages 35 to 40 . Panels D to I of Figure 8 present the trends for age at first birth by gender, marital status, race, and educational group. The main findings are as follows: (i) In general, there was an increase in age at first birth, for both men and women, from 1968 until the late 2000s; the age then started to decline in 2011 and 2013 for men and women, respectively (Panel D). (ii) The same pattern is found for men and women ever married (by age 35); therefore, there is no difference in the age at first birth between never and ever-married individuals (Panel E). (iii) By race, Black men generally have been younger at first birth than White men; although this gap had been closing over the early part of the sample up to 2000, the trend reversed, with the gap widening (Panel F). For women, the age at first birth increased from 1968 to 2013, with a slight decline after 2013 for White women; however, the age at first birth for Black women has remained essentially unchanged over the entire sample period 19682015 (Panel G). (iv) By completed education, while the age at first birth differs by education level, the disaggregated trends are similar to the overall trends (Panels $\mathrm{H}$ and I).

These results confirm the long-run trends documented in the literature. In particular, Lundberg and Pollak (2007), using the number of births per 1,000 women as their measure of fertility, find that as the postwar baby boom waned, birth rates for women ages 15 to 44 fell from 118 births per 1,000 women in 1960 to 68 births per 1,000 women in 1980. They also found that women have continued to delay childbearing, confirming the findings in this article on age at first birth. In addition, they find that completed fertility was approximately at the replacement rate of 2.1 children per woman by 2005 , consistent with the results in this article. More recently, Greenwood (2019) suggests that this long-run decline in fertility is explained by the increase in women's wages, which raised the opportunity cost of having children. The 


\section{Figure 8}

Trends in Completed Fertility and Age at First Birth
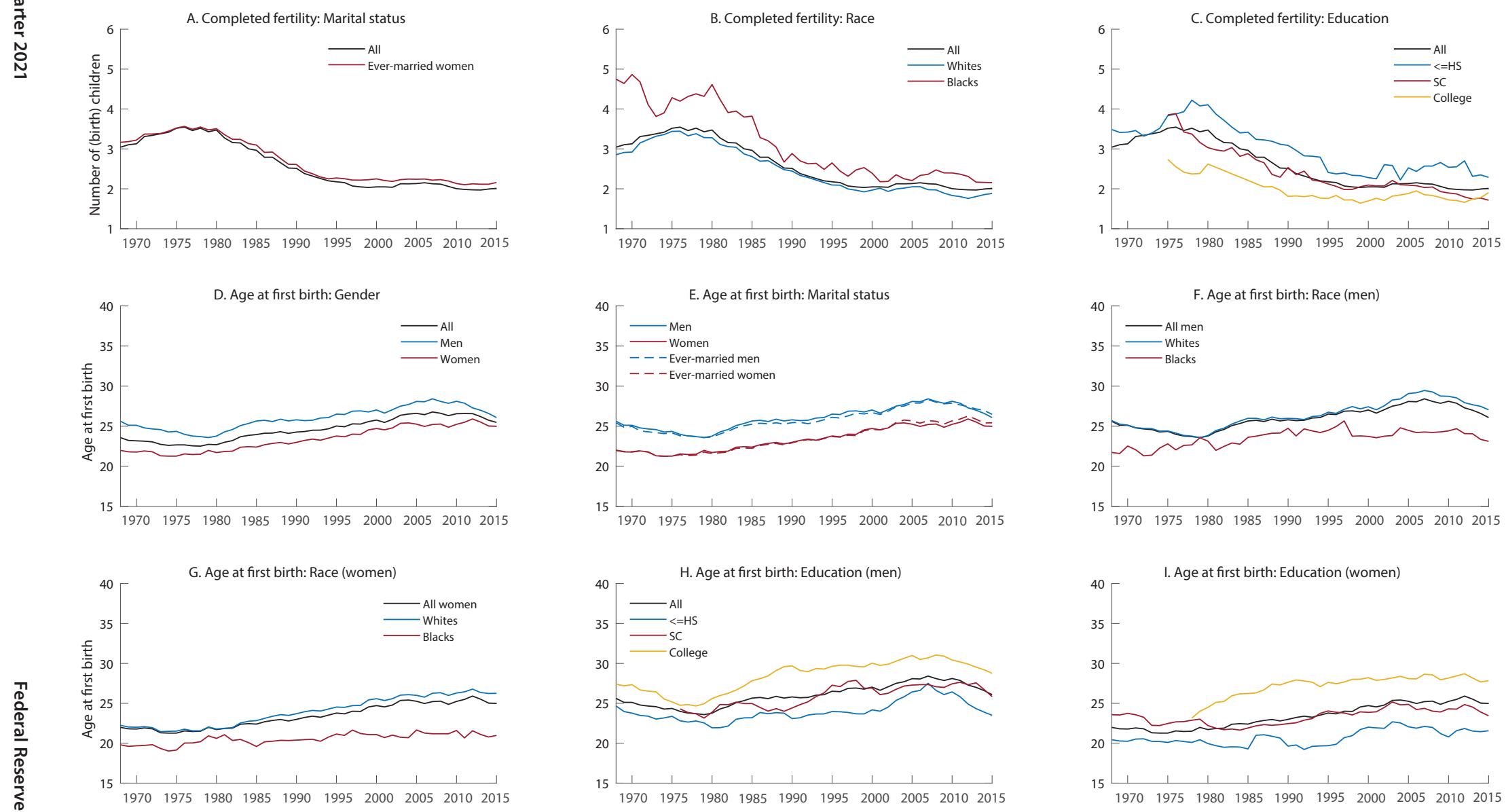

NOTE: All graphs are restricted to head and spouse. The completed fertility graphs are restricted to ages 45 to 50 for completed fertility graphs and the age-at-first-birth graphs to ages 35 to 40 . Marital status refers to individuals ever married by age 45 for completed fertility and by age 35 for age at first birth. <=HS, those with education less than or equal to a high school diploma; SC, those with some college; and College, college graduates (with a four-year degree or higher).

SOURCE: PSID and authors' calculations. 
Table 3

Completed Fertility by Generation

\begin{tabular}{|c|c|c|c|c|}
\hline & \multicolumn{4}{|c|}{ Generation } \\
\hline & Silent & Boomers-1 & Boomers-2 & GenX* \\
\hline Overall & $\begin{array}{c}2.55 \\
(1.79)\end{array}$ & $\begin{array}{c}2.12 \\
(1.44)\end{array}$ & $\begin{array}{c}1.93 \\
(1.41)\end{array}$ & $\begin{array}{c}1.63 \\
(1.34)\end{array}$ \\
\hline \multirow[t]{2}{*}{ Observations } & 11,586 & 23,376 & 18,814 & 325 \\
\hline & \multicolumn{4}{|c|}{ Marital status } \\
\hline Not married & $\begin{array}{c}2.15 \\
(1.77)\end{array}$ & $\begin{array}{c}1.94 \\
(1.51)\end{array}$ & $\begin{array}{c}2.08 \\
(1.54)\end{array}$ & $\begin{array}{c}1.70 \\
(1.28)\end{array}$ \\
\hline Observations & 2,709 & 3,507 & 2,670 & 50 \\
\hline Married & $\begin{array}{c}2.72 \\
(1.78)\end{array}$ & $\begin{array}{c}2.22 \\
(1.39)\end{array}$ & $\begin{array}{c}2.17 \\
(1.34)\end{array}$ & $\begin{array}{c}2.40 \\
(1.30)\end{array}$ \\
\hline \multirow[t]{2}{*}{ Observations } & 6,705 & 7,620 & 4,953 & 86 \\
\hline & \multicolumn{4}{|c|}{ Education } \\
\hline High school dropouts & $\begin{array}{c}3.52 \\
(2.26)\end{array}$ & $\begin{array}{c}2.83 \\
(1.65)\end{array}$ & $\begin{array}{c}2.70 \\
(1.55)\end{array}$ & $\begin{array}{c}2.00 \\
(1.93)\end{array}$ \\
\hline Observations & 2,544 & 3,258 & 2,574 & 30 \\
\hline High school graduates & $\begin{array}{c}2.51 \\
(1.54)\end{array}$ & $\begin{array}{c}2.21 \\
(1.33)\end{array}$ & $\begin{array}{c}1.93 \\
(1.37)\end{array}$ & $\begin{array}{c}1.69 \\
(1.35)\end{array}$ \\
\hline Observations & 3,912 & 8,430 & 6,578 & 106 \\
\hline Some college & $\begin{array}{c}2.25 \\
(1.42)\end{array}$ & $\begin{array}{c}2.02 \\
(1.36)\end{array}$ & $\begin{array}{c}1.81 \\
(1.35)\end{array}$ & $\begin{array}{c}1.59 \\
(1.25)\end{array}$ \\
\hline Observations & 2,478 & 6,390 & 5,561 & 92 \\
\hline College graduates & $\begin{array}{c}1.85 \\
(1.27)\end{array}$ & $\begin{array}{c}1.65 \\
(1.31)\end{array}$ & $\begin{array}{c}1.62 \\
(1.24)\end{array}$ & $\begin{array}{c}1.53 \\
(1.20)\end{array}$ \\
\hline \multirow[t]{2}{*}{ Observations } & 2,316 & 4,860 & 3,755 & 88 \\
\hline & \multicolumn{4}{|c|}{ Race } \\
\hline Whites & $\begin{array}{c}2.29 \\
(1.53)\end{array}$ & $\begin{array}{c}2.00 \\
(1.33)\end{array}$ & $\begin{array}{c}1.80 \\
(1.27)\end{array}$ & $\begin{array}{c}1.49 \\
(1.27)\end{array}$ \\
\hline Observations & 7,668 & 12,942 & 10,208 & 194 \\
\hline Blacks & $\begin{array}{c}2.86 \\
(1.98)\end{array}$ & $\begin{array}{c}2.20 \\
(1.47)\end{array}$ & $\begin{array}{c}1.99 \\
(1.52)\end{array}$ & $\begin{array}{c}1.94 \\
(1.42)\end{array}$ \\
\hline Observations & 2,730 & 8,232 & 6,222 & 95 \\
\hline \multicolumn{5}{|c|}{ NOTE: *The generation has right censoring in terms of age. The table is calculated for women ages 45 to 50 . } \\
\hline
\end{tabular}


Gayle, Odio-Zuniga, Ramakrishnan

\section{Table 4}

Proportion of Births to Married Women and Parity of Births, by Generation and Age

\begin{tabular}{|c|c|c|c|c|c|c|c|c|c|c|}
\hline \multirow[b]{3}{*}{ Age group } & \multicolumn{5}{|c|}{ Proportion of births to married women } & \multicolumn{5}{|c|}{ Parity of births } \\
\hline & \multicolumn{5}{|c|}{ Generation } & \multicolumn{5}{|c|}{ Generation } \\
\hline & Silent & Boomers-1 & Boomers-2 & GenX & Millennials & Silent & Boomers-1 & Boomers-2 & GenX & Millennials \\
\hline $18-20$ & 71.64 & 60.55 & 44.43 & 26.66 & 16.13 & 0.22 & 0.22 & 0.21 & 0.23 & 0.19 \\
\hline $21-25$ & 83.47 & 74.57 & 63.00 & 47.56 & 39.27 & 0.79 & 0.66 & 0.64 & 0.62 & 0.59 \\
\hline $26-30$ & 87.05 & 80.87 & 73.95 & 71.05 & 64.80 & 1.51 & 1.25 & 1.19 & 1.14 & 1.10 \\
\hline $31-35$ & 88.40 & 82.77 & 81.01 & 83.15 & 75.31 & 2.03 & 1.72 & 1.62 & 1.65 & 1.59 \\
\hline $36-40$ & 86.12 & 83.71 & 84.34 & 85.27 & & 2.30 & 1.96 & 1.88 & 1.97 & \\
\hline $41-45$ & 84.98 & 83.41 & 82.54 & 74.47 & & 2.42 & 2.04 & 2.01 & 2.05 & \\
\hline
\end{tabular}

NOTE: Marital status refers to the marital status of a woman at the time of birth.

SOURCE: PSID and authors' calculations.

author calculates completed fertility in the year 1800, where the average White woman had 7 children; yet, by 1990, this number had dropped to just 2 . Finally, he argues that there was a significant recovery in fertility in the mid-1960s, as seen in Panel A of Figure 8 as well. He explains that advances in medicine led to both younger and older women having more children. Fertility then reverted back to its common trend, and the "baby bust" resumed.

Table 3 presents completed fertility by generation for women ages 45 to 50 . There are no results for Millennials, as this generation had not reached ages 45 to 50 by 2015 (when the sample ends). For GenX, there is some right censoring in terms of age; however, the numbers for GenX are still reported in the table. As the table shows, there has been a decreasing trend in completed fertility, with it falling below the replacement rate for Boomers-2. ${ }^{24}$ This trend is seen after disaggregating by marital status, education, or race, with the only exception being unmarried women. The gap in completed fertility between high school dropouts and college graduates has narrowed from 1.67 for the Silent generation to 1.08 for Boomers-2. A similar decline is observed for the difference in completed fertility between Blacks and Whites from the Silent (0.57) to the Boomers-2 (0.19) generation.

In order to analyze the fertility behavior of Millennials, Table 4 presents data on parity of births as well as the proportion of births to married women across generations. It is evident that non-marital fertility, as measured by the proportion of children born to unmarried women, has risen for all four Millennial age groups (spanning ages 18 to 35). This finding is in line with the rise in non-marital fertility reported by Lundberg and Pollak (2007), who state that 37 percent of U.S. births were out-of-wedlock in 2005. The parity of births presents the evolution of fertility over the life cycle and is defined as the number of live births to a woman so far. At the youngest age group, Millennials start at a much lower parity than any other generation and remain so for the other three age groups. 


\subsection{Marriage}

This article uses two different measures of marital status: (i) legally married, defined as stated-individuals who are legally married, and (ii) PSID married, defined as those individuals who are either legally married or have a cohabiting partner. .5 The marriage rate corresponds to the proportion of individuals ages 18 to 65 who are legally married. A similar definition is used for PSID marriage rates using PSID married. Figure 9 presents the marriage rates by gender, race, and educational level.

There is an active literature that has documented the decline in marriage rates over time (see Greenwood and Guner, 2008; Lundberg and Pollak, 2015; Lundberg, Pollak, and Stearns, 2016; Santos and Weiss, 2016; and Greenwood, 2019). Panel A of Figure 9 also confirms the decline of the overall marriage rates for the period 1968-2015. Panels B and C of Figure 9 present the marriage rate by race. It shows that Whites marry at a higher rate than Blacks and that this racial gap in marriage rates has widened over time. Panels B and C of Figure 9 also show a larger decline in marriage rates over time for Blacks relative to Whites. For example, in 1968, the gap between White and Black marriage rates was 3.3 percentage points for men; by 2015 , this gap had increased to 23.6 percentage points. Similarly, that gap for women rose from 6.4 percentage point to 31.2 percentage points over the same period. Panel D of Figure 9 shows an increase in cohabitation; however, this rate tends to be small: It was 0.6 percent in 1968 and by 2015 had increased to 5.9 percent. This finding is in line with the discussion by Lundberg, Pollak and Stearns (2016), where they point out that over time there has not only been a "retreat from marriage" but also an increase of cohabitation by many "single" Americans. Finally, for both definitions of marriage (legally and PSID), there is a similar pattern by educational level, implying that cohabitation does not have a significant impact on the overall trend of household formation (Panels $\mathrm{E}$ to $\mathrm{H}$ ). While all education groups have seen a decline in marriage rates, the rate has declined more slowly for college graduates. Moreover, there was a crossover in marriage rates for both men and women college graduates in the years 1987 and 1998, respectively; that is, before 1987 and 1998, college graduates married at a lower rate than all other education groups but after 1987 and 1998 the opposite has been true. Greenwood (2019) also pointed out that the decline in marriage rates are greater for the non-college graduates than for the college graduates, while Lundberg and Pollak (2007) found that the marriage-rate trajectories of the more and less educated began to diverge in the mid-1980s.

The decline in marriage rates is clear, yet it raises the question as to what the driving forces are behind the decline. Greenwood (2019) discusses that there exist three possible explanations in the literature. First, as previously mentioned, there has been a rise in wages, which makes a one-person household more affordable. Second, the labor-saving technological progress in the home has led to less need for specialization (Greenwood and Guner, 2008). Finally, there has been a fast drop in the prices of time-saving goods used at home. The authors argue that these three forces reduced the importance of scale economies in household consumption/production; hence, single households are more common in the current time. In addition, Santos and Weiss (2016) propose that because the childcare costs that parents have to incur are fixed and difficult to avoid during tough economic times, people delay marriage when there is instability in the labor market. 


\section{Figure 9}

Trends in Marriage Rates and Age at First Union
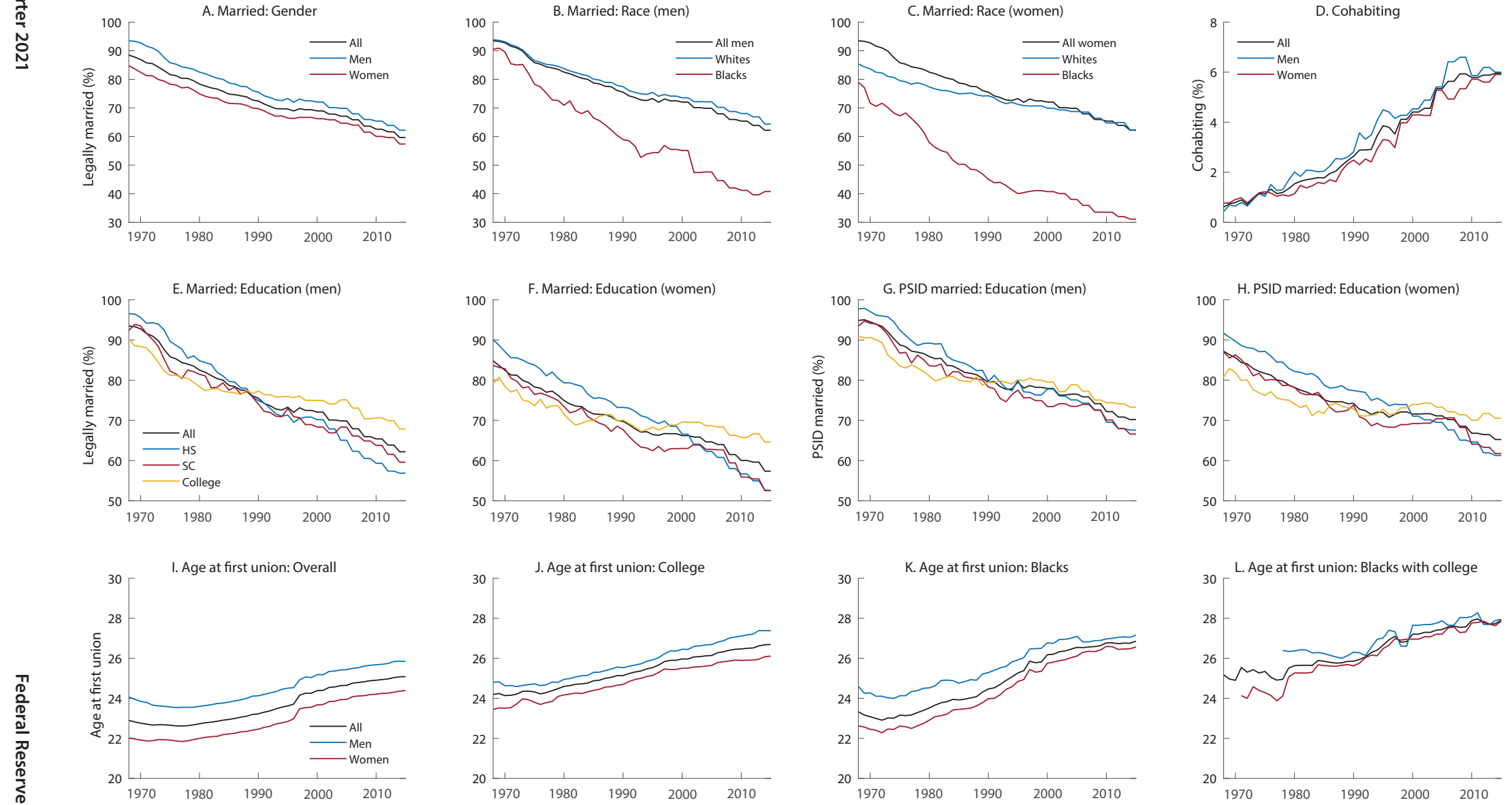

NOTE: All graphs are restricted to head and spouse and to ages 18 to 65 . Married refers to legally married, while PSID married refers to married or cohabiting individuals. In Panels $\mathrm{E}$ to $\mathrm{H}$, "All" includes high school dropouts plus the following: HS, high school graduates; SC, those with some college; and College, college graduates (with a four-year degree or higher).

SOURCE: PSID and authors' calculations. 


\section{Figure 10}

\section{Marriage Rates by Generation}
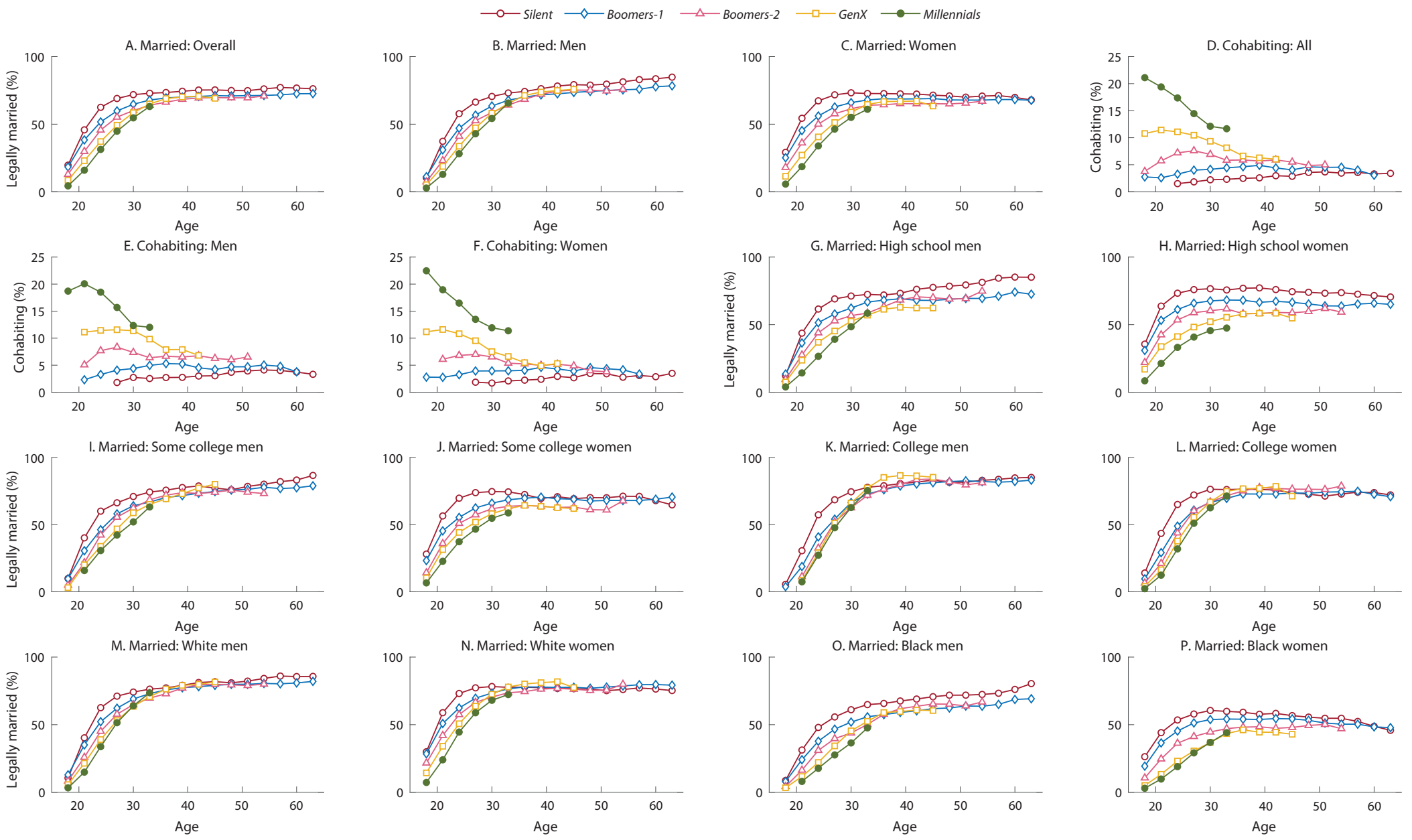

NOTE: All graphs are restricted to head and spouse. Married refers to legally married. The generation graphs are also restricted to ages 18 to 65 and are plotted for three age-group intervals for smoothing of the trend. For example, age 18 refers to the 18-20 age group. High school, high school graduates; Some college, those with some college; and College, college graduates (with a four-year college degree or higher).

SOURCE: PSID and authors' calculations. 


\section{Gayle, Odio-Zuniga, Ramakrishnan}

To complement this analysis, this article also presents the "age at first union," which is defined as the age when the individuals got married or started cohabiting with their partner for the first time. Panels I to L of Figure 9 present the trends for this variable by gender, educational group, and race. The age at first union has increased over time for men and women. Moreover, college graduates tend to further delay their first union, possibly due to human capital accumulation. For example, in 2015, men (women) high school graduates had their first union on average at age 24.7 (23), while men (women) college graduates had their first union on average at age 27.4 (26.1). Finally, Panel K shows that over time Black women have delayed their age at first union and, thus, the gap in the age at first union between Black men and Black women has narrowed. $\underline{26}$

Figure 10 presents the life-cycle trends of marriage rates over generations. It shows a sharp decline in marriage rates over generations as well as a flattening over the life cycle, with Millennials having the lowest marriage rates among all generations at all comparable ages (Panel A). Cohabitation rates have risen over each generation, with Millennials having the highest rates. The rate rose from 2.3 percent (2.8 percent) to 11 percent (12 percent) for men (women) ages 21 to 23 from Boomers-1 to Millennials. In line with Lundberg and Pollak (2007), the less-educated groups (some college and less) have retreated from marriage. This is because the life-cycle trends for each generation are clearly below the previous one, with Millennials being the most distinct. It could be the case the less-educated individuals are ruling themselves out of the marriage market (Lundberg and Pollak, 2007). However, for college graduates, Figure 10 shows a delay in marriage instead of a retreat from marriage, since by ages 30 to 33 , Millennials have caught up to the marriage rates of the previous generations. The patterns are similar across Black men and White men; however, Black Millennial women see a catching up of the marriage rate by ages 30 to 33 .

Framework for Analyzing Education and Marriage. It is clear from the previous trends and is well documented in the literature (Chiappori, Salanié, and Weiss, 2017, and Gayle and Shephard, 2019, among others) that education plays an important role in the marriage market. This section presents an empirical framework for how an individual chooses a partner of a certain education level or remains single in a frictionless marriage market. The framework is the multinomial logit empirical analog of the equilibrium marriage market model in Choo and Siow (2006), Chiappori, Salanié, and Weiss (2017), and Gayle and Shephard (2019) and is summarized by the log-odd ratio of marrying a partner of a particular type and singlehood:

$$
\log \left[\frac{P\left(m_{i t}=j\right)}{P\left(m_{i t}=0\right)}\right]=\alpha_{0}^{j}+\sum_{r=1}^{4} \alpha_{1}^{j} d_{i, t-r}+\sum_{r=1}^{4} \alpha_{2}^{j} h_{i, t-r}^{m}+\boldsymbol{\delta}^{j} \mathbf{Z}_{\mathbf{i t}},
$$

where $P\left(m_{i t}=j\right)$ refers to the probability that individual of gender $i$ chooses a partner of type $j$ in calendar time $t$. The index $j$ indexes the type of partner, where choosing to remain single is the baseline $(j=0)$. In the empirical implementation, partners are indexed by three levels of educational attainment as follows: high school diploma or less $(j=1)$, some college $(j=2)$, and college graduate (with a four-year degree or higher) $(j=3)$. The regression also includes controls $\left(\mathbf{Z}_{\mathrm{it}}\right)$, which are age, age squared, race, education, and number of children. Educational 
Gayle, Odio-Zuniga, Ramakrishnan

\section{Table 5}

\section{Averages Used in the Multinomial Logit}

\begin{tabular}{|c|c|c|c|c|c|}
\hline & Silent & Boomers-1 & Boomers-2 & GenX & Millennials \\
\hline Number of children & $\begin{array}{c}2.05 \\
(1.44)\end{array}$ & $\begin{array}{c}1.70 \\
(1.24)\end{array}$ & $\begin{array}{c}1.63 \\
(1.26)\end{array}$ & $\begin{array}{c}1.78 \\
(1.32)\end{array}$ & $\begin{array}{c}1.58 \\
(1.33)\end{array}$ \\
\hline Participation in past four periods & $\begin{array}{c}2.66 \\
(1.54)\end{array}$ & $\begin{array}{c}2.69 \\
(1.49)\end{array}$ & $\begin{array}{c}2.80 \\
(1.48)\end{array}$ & $\begin{array}{c}3.19 \\
(1.33)\end{array}$ & $\begin{array}{c}3.42 \\
(1.15)\end{array}$ \\
\hline Hours worked in past four periods / 10 & $\begin{array}{c}377.62 \\
(309.76)\end{array}$ & $\begin{array}{c}394.62 \\
(310.74)\end{array}$ & $\begin{array}{c}443.36 \\
(324.22)\end{array}$ & $\begin{array}{c}540.73 \\
(329.40)\end{array}$ & $\begin{array}{c}574.13 \\
(300.56)\end{array}$ \\
\hline
\end{tabular}

NOTE: A multinomial logit regression is run where the dependent variable categories are based on the marital status of the individual: Single (unmarried); $<=\mathrm{HS}$, married to a partner with high school diploma or less; SC, married to a partner with some college; and College, married to a partner that is a college graduate (with a four-year degree or higher). The key explanatory variable is on the education of the woman (man) and the following controls are included: age, age squared, race, number of children, employment in the past four periods, and hours worked in the past four periods.

SOURCE: PSID and authors' calculations.

attainment of the individual is categorized the same as the education attainment of the partners. ${ }^{27}$ All other variables are as defined in equation (1). The marriage transition analysis is done separately for each gender and cohort, and the data are restricted to Blacks and Whites between ages 20 and 40, as most marriages take place during these years.

What Predicts Partner Choice? This analysis focuses on the role that education plays in partner choice. Panels A, B, E, and F of Figure 11 plot the observed marriage and education transitions for women ages 30 to 35 by generation. Although the regression is run for the 20-40 age group, we focus on the 30-35 age group for this analysis because most education is completed by then. It is clear from these panels that irrespective of race or education, singlehood has risen over the generations. While this has been a monotonically increasing trend for women with a high school diploma or less (Panel A), White GenX women and Black Boomers-1 women college graduates each had a reduction in singlehood relative to the previous generation (Panels B and F, respectively). Another striking feature to note is the differences in the rates of singlehood across race and education. For White GenX women, while 27.3 percent of those with a high school diploma or less are single, the number shrinks to 16.7 percent for college graduates. The equivalent numbers for Black women are 65 percent and 48.5 percent, respectively, which are significantly larger.

Panels I, J, M, and N of Figure 11 plot the model-predicted marriage and education transitions for women age 35 by generation, using the specification, as defined in equation ( 3 ), where the remaining variables (unless stated otherwise) are set to their average values. $\underline{28}$ While the model underpredicts the singlehood rates for White women, specifically for those that are college graduates in the generations beyond Boomers-1, it overpredicts the rate for Black women, specifically for those that are Boomers-1 college graduates. A reason for this could be the lack of observations in these categories, specifically college graduates in the earlier generations. 
Predicted Probability of Choosing a Partner, by Educational Attainment
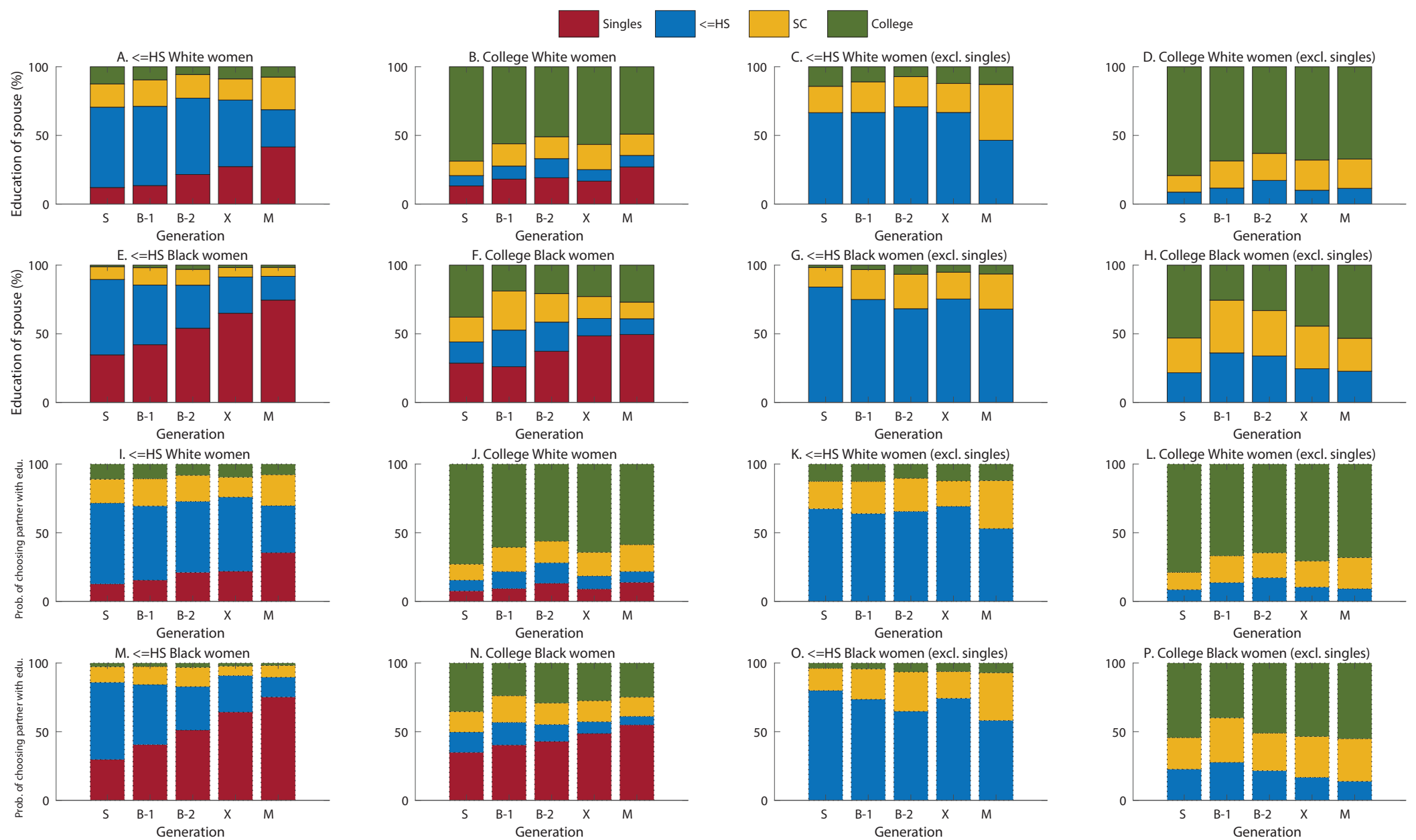

NOTE: All graphs are restricted to head and spouse. A multinomial logit regression is run where the dependent variable categories are based on the marital status of the individual: Single; $<=\mathrm{HS}$, married to a partner with high school diploma or less; SC, married to a partner with some college; and College, a married to partner that is a college graduate (with a four-year degree or higher). The key explanatory variable is on the education of the woman (man) and the following controls are included: age, age squared, race, number of children, employment in the past four periods, and hours worked in the past four periods. S, Silent generation; B-1, Boomers-1; B-2, Boomers-2; X, GenX; and M, Millennials. SOURCE: PSID and authors' calculations. 
To tease out the assortative mating patterns, the analysis now focuses on women who do get married. Panels C, D, G, and H of Figure 11 show the empirical patterns, while Panels K, $\mathrm{L}, \mathrm{O}$, and $\mathrm{P}$ show the model-predicted patterns. Assortative mating is defined here as individuals of the same education level marrying each other, for example, college graduates marrying each other. While there is no clear trend in terms of a rise or fall in assortative mating over generations, there is no doubt that assortative mating exists in the data and is predicted by the model as well. Averaging over generations, White women with a high school diploma or less have a 63.5 percent likelihood of assortative mating; for those that are college graduates, the number rises to 69.2 percent. On the other hand, averaging across generations, assortative mating is more pronounced for Black women with a high school diploma or less (74.1 percent), but less pronounced for those that are college graduates (41.8 percent). However, note that singlehood rates are significantly higher for Black women as well. Focusing on the model predictions, note that the model under predicts assortative mating for women with a high school diploma or less and over predicts for those that are college graduates. The overpedictions are more notable for Black women.

\subsection{Divorce}

Any discussion of marriage without talking about divorce would be incomplete. The divorce rate in this article is defined as the proportion of individuals ages 18 to 65 who are not legally married in the current period but were married in the previous period.

Panels A and B of Figure 12 plot a smoothed version of the divorce rate by fitting a quadratic time trend to the raw data. An inverted-U-shaped trend is seen for "All" for the years 1968 to $2015, \underline{29}$ with the divorce rate falling post 2000, reaching 1.69 percent in 2015. This trend is directly affected by the declining marriage rate, as discussed in Section 5.2. Lundberg and Pollak (2015) find that the divorce rate peaked in the 1980s. However, they use the number of divorces per thousand married couples and the data are from the U.S. Census and the American Community Survey, which are repeated cross-sections and, therefore, can analyze marriage and divorce patterns only for a point in time. They also argue that the increase from 1960 to 1980 is in part explained by liberalized divorce laws, where unilateral divorce became universal across the country, as well as the decrease in the social and legal costs of exiting a marriage. $\frac{30}{}$ Disaggregating by education groups, it is clear that college graduates divorce the least relative to the other education categories. Analysis by race shows that Blacks divorce at significantly higher rates than Whites (Panel B).

To complement these findings, a survival analysis is performed by estimating a kernel regression of divorce on years of marriage (or marriage tenure). Three additional restrictions are imposed: First, the survival analysis is conducted at the household level; second, only marriages where the ages upon marriage of both the husband and wife were between 18 and 65 are considered; and third, marriage tenure is plotted to 35 years to circumvent the possibility of the marriage ending due to the death of a spouse. Panels $\mathrm{C}$ to J of Figure 12 present the survival analysis by race, education, and generation. Overall, the probability of divorce peaks in the first eight years of marriage and then decreases monotonically (Panel C). This decrease indicates strong duration dependence; that is, the longer the duration of the marriage, 


\section{Divorce Rates: Trends and Generations}
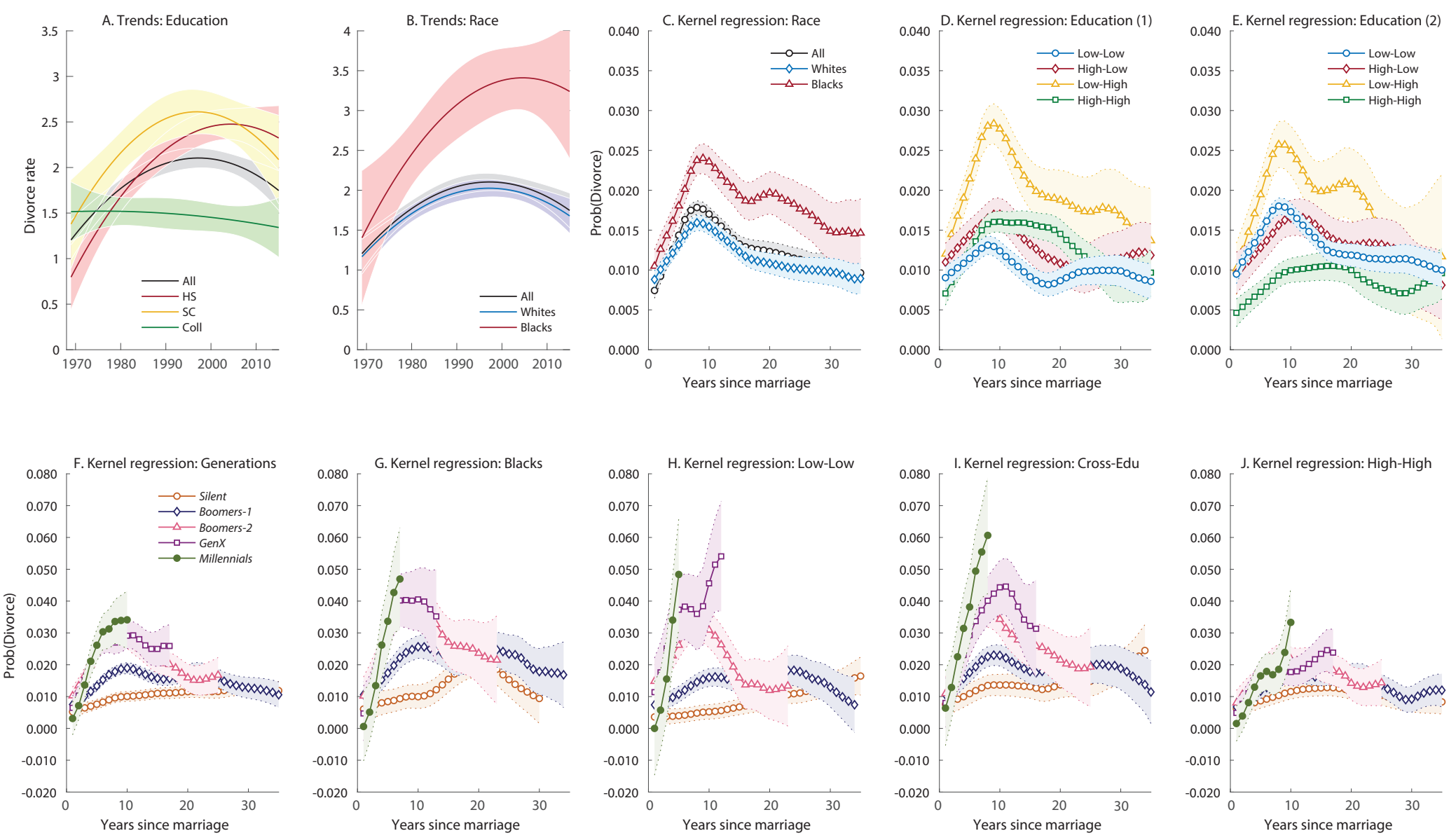

NOTE: The graphs are restricted to head and spouse for the trend graphs and to households for the kernel regressions of divorce (defined as divorce or death). The generation graphs are also restricted to ages 18 to 65 and are plotted for three age-group intervals for smoothing of the trend. For example, age 18 refers to the $18-20$ age group. In Panel A, "All" includes high school dropouts plus the following: HS, high school graduates; SC, those with some college; and Coll, college graduates (with a four-year degree or higher). Prov(Divorce), probability of divorce. In Panel D, "low" refers to completed education of less than or equal to a high school diploma and "high" refers to completed education of some college or above. In Panel E, "low" refers to completed education less than a four-year college degree and "high" refers to completed education of a four-year college degree or higher. Then, for each definition of education, the four groups of couples are low-low, high-low, low-high, and high-high, where the first component corresponds to the education type of the husband and the latter to the wife. Panel I, "Cross-Edu," combines the high-low and low-high education groups of Panel D since their patterns do not differ.

SOURCE: PSID and authors' calculations. 
the lower the likelihood of divorce. Although this pattern holds by race, Blacks have a significantly higher likelihood of divorcing than Whites. For example, after nine years of marriage, Blacks have a 2.4 percent probability of getting divorced compared with 1.6 percent for Whites.

Education is an important factor in marriage rates, as seen in the previous section, where college graduates delayed marriage but non-college graduates retreated from it. The education of the couples is classified according to two different definitions of education, each with "low" and "high" education types: Education 1, where low refers to completed education of less than or equal to a high school diploma and "high" refers to completed education of some college or above, and Education 2, where "low" refers to completed education less than a four-year college degree and "high" refers to completed education of a four-year college degree or higher. Then, for each definition of education, the four groups of couples are low-low, high-low, low-high, and high-high, where the first component corresponds to the education type of the husband and the latter to the wife. Panels D and E of Figure 12 break out the probability of divorce by the education definitions and types.

Using the Education 1 definition, the assortatively matched pairs (low-low and high-high) have the lowest probability of divorce during the first 10 years of marriage. However, couples where the woman "marries down" (low-educated husband with a high-educated wife) have the highest probability of divorce. For example, at nine years of marriage, the divorce rate for the low-high group is 2.8 percent, which is more than double the rate for the low-low group (1.3 percent). One explanation is that when the wife has more education than the husband, she will have a higher outside option, which can lead to divorce. This finding is in line with Bertrand, Kamenica, and Pan (2015), who argue that households where the wife earns more than the husband tend to have a higher probability of divorce, in part due to gender identity norms such as the husband should be the breadwinner.

Panel E of Figure 12 uses the Education 2 definition. The key difference is that high-high couples have the lowest divorce rates, which is significant in the early years of the marriage. However, low-high couples still stand out due to their significantly higher rates relative to the other education pairs. These patterns confirm the results in Lundberg, Pollak, and Stearns (2016), who find that college-graduate parents have the lowest divorce rates and use marriage as a commitment device to facilitate joint investment in their children. $\underline{31}$

Using the generation of the husband as the generation of the household, Panels F to J present the divorce rates by generation. $\frac{32}{2}$ It is important to note that long-term marriage analysis for the younger generations, especially Millennials, is not yet possible. The Silent generation has a very flat profile with minimal duration dependence, indicating that their probability of divorce is stable and does not change significantly as marriage tenure increases (Panel F). For Boomers-1, the divorce rate increased relative to the Silent generation and has more pronounced duration dependence. Although there is not much statistical difference in the probability of divorce for Boomers-2 and later generations, Millennials are the most likely to divorce after five years of marriage. Stevenson and Wolfers (2007) find similar results using the retrospective marriage history from the Survey of Income and Program Participation. They show that the proportion of marriages that end in divorce increases for each successive marriage cohort $\underline{33}$ from 1950-59 to 1970-79 and then subsequently falls for the 1980-89 and 


\section{Gayle, Odio-Zuniga, Ramakrishnan}

1990-99 cohorts. The pattern is similar across Blacks and Whites, although Blacks have higher divorce rates. Therefore, the major changes in divorce rates across generations are primarily coming from Blacks and not necessarily Whites (Panel G).

Finally, Panels $\mathrm{H}$ to J of Figure 12 show divorce rates by generation and education type using the Education 1 definition. $\underline{34}$ High-high couples (Panel J) have significantly lower divorce rates than couples where at least one spouse is of low education (Panel I). Thus, most of the changes in divorce rates across generations come from these three couple types: low-low, low-high, and high-low. This finding cannot be viewed in isolation, as the marriage rate for less-educated individuals has changed over time. As discussed in Section 5.2, the singlehood rate is what has changed and not the sorting pattern; that is, fewer less-educated individuals are getting married, implying that the composition of the education types of married couples has been changing over time.

\section{CONCLUSION}

This article analyzes the changes in family structure, fertility behavior, and the division of labor within the household over generations. Using PSID data, it documents time trends and life-cycle profiles over generations on three aspects-work, family, and leisure. This article provides a first cut on the behavior of Millennials and how they compare with previous generations.

Focusing on work, it finds that the wage-age profile has been shifting down over generations, especially for Millennial men (up to age 33). However, women's wages have instead stagnated, with Millennial women earning lower wages than Generation $X$ after age 30. Therefore, rising wage inequality has come from men and not women. To understand the decomposition of the gender gap in wages, an Oaxaca-Blinder decomposition is estimated, which decomposes the gender wage gap into explained and unexplained components. For ages 18 to 65 , there is a sharp fall in the unexplained component over the generations, from 30.5 percent for the Silent generation to 8.5 percent for Millennials.

The reversal in the gender gap in education is well documented; however, this switch occurred in the Boomers-2 generation, since up to Boomers-1, men were graduating from college at higher rates than White women. Focusing on race, there has also been a significant increase in college graduation rates from Boomers-2 to GenX for both Blacks and Whites, a pattern that has continued to accelerate for Millennials. This is in sharp contrast to the generally stable graduation rate from the Silent generation to Boomers-1. The article also finds a significant reduction in high school dropout rates, which has been most pronounced for Blacks. The percentage of Black high school dropouts fell from 27.5 percent for the Silent generation to 7.1 percent for Millennials. The article also estimates the returns to education over generations, especially given the changing educational attainment and narrowing of gender wage gaps. For both Black men and White men, the returns to college have increased for all generations, with the most significant increase for Black Millennial men. For women, the trend is less clear.

With respect to leisure, the article finds that over generations, while the amount of leisure enjoyed by women has been increasing, the amount of leisure enjoyed by men shows no clear 
pattern. However, for both men and women, Millennials enjoy a higher level of leisure than previous generations. This rise in leisure for women is primarily coming from married women. The finding that the amount of leisure enjoyed by men has been stable over generations masks different dynamics in the components of leisure. There has been a significant reduction in hours worked by men, with Millennials working the least. At the same time, there has been an increase in the hours men devote to housework, with Millennial men devoting more hours than men in any previous generation. The opposite is true for women: Their reduction in housework hours over generations has more than offset the increase in hours devoted to market work. More importantly, most of this movement for women has occurred within married couples. To understand what predicts housework hours, the article controls for race, education, gender, marital status, the numbers of young and old children, and age. It finds that young and old children in a household have a significant impact on housework hours, especially young children.

The article finds that marriage (and thus, fertility) has seen many drastic changes over generations. Less-educated individuals have retreated from marriage, especially those that are Millennials. Yet it is not clear whether Millennials would be marrying at an overall rate lower than previous generations, as the composition of education has also changed, with a much higher number of Millennial college graduates. Using a multinomial logit to predict partner choice, no clear trends in assortative matching are seen over generations. Although this finding is in contrast to those of Greenwood and Guner (2008) and Santos and Weiss (2016), it is in line with the those of Gihleb and Lang (2016). With respect to cohabitation, for GenX and Millennials, cohabitation rates are much higher early on in life relative to previous generations; nevertheless, later on, it drops off significantly, indicating cohabitation has been transitory-a pattern not seen for the Silent and Boomer generations.

Any changes in marriage patterns will also affect divorce rates. For the period 1968-2015, divorce rates follow an inverted- $U$ shape, with college graduates divorcing the least. As argued by Lundberg, Pollak, and Stearns (2016), some of the reasons for this trend are the declining marriage rate, the transition to unilateral divorce laws, and the decrease in the social and legal costs of exiting a marriage. The present article also finds that couples where the woman marries down (a low-educated husband with a high-educated wife) have the highest probability of getting a divorce. A possible explanation is due to gender identity norms such as the husband should be the breadwinner, which is in line with the findings of Bertrand, Kamenica, and Pan (2015). Analysis across generations finds that the Silent generation has a very flat divorce profile with minimal duration dependence, whereas the remaining generations have a subsequent increase in divorce as well as more pronounced duration dependence, with Millennials having the highest probability of divorce after five years of marriage. The majority of the changes in divorce across generations primarily come from Blacks and couples where at least one spouse has completed education of less than or equal to a high school diploma.

Finally, the results in the article confirm the significant decline in completed fertility, with the fertility rates of Boomers- 2 and GenX falling below the replacement rate. Similar trends exist across races (see Lundberg and Pollak, 2007, and Greenwood, 2019). There has been a steady decline at each age parity of the proportion of births to married women, although this decline has accelerated among Millennials. The article also finds that the completed Millennial fertility rate will most likely be below those of all generations analyzed in this article. 


\section{Gayle, Odio-Zuniga, Ramakrishnan}

\section{NOTES}

1 Millennials are normally defined as a person reaching young adulthood in the early twenty-first century. For the analysis in this article, Millennials are defined as a person born in the birth cohort from 1980 to 1989.

2 See Kong, Ravikumar, and Vandenbroucke (2018) for similar results in the flattening of the age-earnings profile for previous generations.

$\underline{3}$ This is similar to the result in Blau and Kahn (2017), who also documented that women are doing better than men.

4 Using data on the pre-Millennial generations Chiappori, Salanié, and Weiss (2017) document similar results.

5 See Lundberg and Pollak (2007), Greenwood and Guner (2008), Lundberg and Pollak (2015), Santos and Weiss (2016), Chiappori, Salanié, and Weiss (2017), and Greenwood (2019), among others, for similar findings.

6 See Lundberg and Pollak (2007) and Greenwood (2019) for similar findings.

$\underline{7}$ These are unweighted numbers.

$\underline{8}$ Married men are employed at a higher rate than single men while married women are employed at a lower rate than single women.

9 Greenwood (2019) argues that the "decline in fertility, improvements in household technologies, advances in obstetric and pediatric medicine have reduced the time off of work that a woman needs to bear and raise children."

10 For the PSID the data regarding the employment status is not available for ages 10 to 13.

11 Blau and Kahn (2017) use data from the Current Population Survey and define individuals ages 16 and older as the working-age population.

12 The data sources are different: They use Current Population Survey data, whereas this article uses PSID data.

13 Aguiar and Hurst (2007) define total market work as total time spent working in the market sector on main jobs, second jobs, and overtime, including any time spent working at home plus commuting and break times.

14 Prior to 1993, farm income and the labor portion of business income were included in individual income, by construction. Post 1993, these are reported as separate amounts. However, individual income is created by adding up the business and farm income so that it is consistent across years.

15 This includes all variables that vary by individuals but are time invariant, for example, completed education, race, and gender.

16 As this article uses log hourly wages, the difference between the men and women log wages is taken.

17 Total time endowment is set at $365.25 \times 24$ hours.

18 While Reid et al. (1934) was the first person to introduce the notion of household production, Becker (1965) was the first to formalize it.

19 Ramey and Francis (2009) define home production as the time spent in planning; purchasing goods and services (except medical and personal care services); care of children and adults; general cleaning; care and repair of the house and grounds; preparing and clearing food; and making, mending and laundering of clothing and other household textiles.

$\underline{20}$ The five surveys are: 1965-1966 American Use of Time; 1975-1976 Time Use in Economics and Social Accounts; 1985 Americans' Use of Time; 1992-1994 National Human Activity Pattern Survey; and 2003 American Time Use Survey.

$\underline{21}$ Core non-market work is defined by Aguiar and Hurst (2007) as "any time spent on meal preparation and cleanup, doing laundry, ironing, dusting, vacuuming, indoor household cleaning, and indoor design and maintenance (including painting and decorating)."

$\underline{22}$ This measure of leisure corresponds to Leisure Measure 1 from Aguiar and Hurst (2007), which includes activities related to "entertainment/social activities/relaxing" and "active recreation."

$\underline{23}$ For more details, see Table 1.2 in Aguiar and Hurst (2007).

$\underline{24}$ All of this generation had not reached age 50 by the end of the sample; however, conclusions can be drawn based on averages. 
$\underline{25}$ The construction of cohabitation is explained in Section 2.

$\underline{26}$ Using the PSID, Schneider, Harknett, and Stimpson (2018) analyze the driving forces of the decline in the rate of entry into first marriage for the 1969-2013 period for different cohorts. They argue that part of the decline is due to a decrease in economic prospects in the labor market and higher probabilities of incarceration for men.

27 This way of categorizing education is used in this section of the article because there are very few women who are high school dropout in the data. Hence, in order to obtain enough data to analyze marriage transitions, high school dropouts and high school graduates are placed in the same category.

$\underline{28}$ The averages are presented in Table 5.

$\underline{29}$ A similar pattern was found in Pessin (2018).

$\underline{30}$ See Eckstein, Keane, and Lifshitz (2019) as well.

$\underline{31}$ See Pessin (2018) as well.

$\underline{32}$ The data are restricted to the years since marriage, where the number of observations is greater than or equal to 100.

33 The results in this article are for birth cohort, or generation.

$\underline{34}$ Panel I of Figure 12 combines the high-low and low-high groups since their patterns do not differ. This joint group is called "Cross-Edu" in the graph.

\section{REFERENCES}

Aguiar, Mark and Hurst, Erik. "Measuring Trends in Leisure: The Allocation of Time Over Five Decades." Quarterly Journal of Economics, 2007, 122(3), pp. 969-1006; https://doi.org/10.1162/qjec.122.3.969.

Aguiar, Mark; Hurst, Erik and Karabarbounis, Loukas. "Recent Developments in the Economics of Time Use." Annual Review of Economics, 2012, 4(1), pp. 373-97; https://doi.org/10.1146/annurev-economics-111809-125129.

Altuğ, Sumru and Miller, Robert A. "The Effect of Work Experience on Female Wages and Labour Supply." Review of Economic Studies, 1998, 65(1), pp. 45-85; https://doi.org/10.1111/1467-937X.00035.

Becker, Gary S. "A Theory of the Allocation of Time." Economic Journal, 1965, pp. 493-517; https://doi.org/10.2307/2228949.

Bertrand, Marianne; Kamenica, Emir and Pan, Jessica. "Gender Identity and Relative Income Within Households." Quarterly Journal of Economics, 2015, 130(2), pp. 571-614; https://doi.org/10.1093/qje/qjv001.

Blau, Francine D. and Kahn, Lawrence M. "The Gender Wage Gap: Extent, Trends, and Explanations." Journal of Economic Literature, 2017, 55(3), pp. 789-865; https://doi.org/10.1257/jel.20160995.

Chiappori, Pierre-André; Salanié, Bernard and Weiss, Yoram. "Partner Choice, Investment in Children, and the Marital College Premium." American Economic Review, 2017, 107(8), pp. 2109-67; https://doi.org/10.1257/aer.20150154.

Choo, Eugene and Siow, Aloysius. "Who Marries Whom and Why." Journal of Political Economy, 2006, 114(1), pp. 175-201; https://doi.org/10.1086/498585.

Eckstein, Zvi; Keane, Michael and Lifshitz, Osnat. "Career and Family Decisions: Cohorts Born 1935-1975." Econometrica, 2019, 87(1), pp. 217-53; https://doi.org/10.3982/ECTA14474.

Gayle, George-Levi and Golan, Limor. "Estimating a Dynamic Adverse-Selection Model: Labour-Force Experience and the Changing Gender Earnings Gap 1968-1997." Review of Economic Studies, 2012, 79(1), pp. 227-67; https://doi.org/10.1093/restud/rdr019.

Gayle, George-Levi and Miller, Robert A. "Life-Cycle Fertility and Human Capital Accumulation." Working paper, Tepper School of Business, 2006.

Gayle, George-Levi and Shephard, Andrew. "Optimal Taxation, Marriage, Home Production, and Family Labor Supply." Econometrica, 2019, 87(1), pp. 291-326; https://doi.org/10.3982/ECTA14528. 


\section{Gayle, Odio-Zuniga, Ramakrishnan}

Gihleb, Rania and Lang, Kevin. "Educational Homogamy and Assortative Mating Have Not Increased." NBER Working Paper 22927, National Bureau of Economic Research, 2016; https://doi.org/10.3386/w22927.

Goldin, Claudia; Katz, Lawrence F. and Kuziemko, llyana. "The Homecoming of American College Women: The Reversal of the College Gender Gap." Journal of Economic Perspectives, 2006, 20(4), pp. 133-56; https://doi.org/10.1257/jep.20.4.133.

Greenwood, Jeremy. Evolving Households: The Imprint of Technology on Life. MIT Press, 2019; https://doi.org/10.7551/mitpress/11268.001.0001.

Greenwood, Jeremy and Ananth, Seshadri. "Technological Progress and Economic Transformation," in Handbook of Economic Growth. Volume 1. Elsevier, 2005, pp. 1225-73; https://doi.org/10.1016/S1574-0684(05)01019-1.

Greenwood, Jeremy and Guner, Nezih. "Marriage and Divorce Since World War II: Analyzing the Role of Technological Progress on the Formation of Households," in NBER Macroeconomics Annual. Volume 23. National Bureau of Economic Research, 2008, pp. 231-76; https://doi.org/10.1086/593087.

Kong, Y-C; Ravikumar, B. and Vandenbroucke, Guillaume. "Explaining Cross-Cohort Differences in Life-Cycle Earnings." European Economic Review, 2018, 107, pp. 157-84; https://doi.org/10.1016/j.euroecorev.2018.06.005.

Lundberg, Shelly and Pollak, Robert A. "The American Family and Family Economics." Journal of Economic Perspectives, 2007, 21(2), pp. 3-26; https://doi.org/10.1257/jep.21.2.3.

Lundberg, Shelly; Pollak, Robert A. and Stearns, Jenna. "Family Inequality: Diverging Patterns in Marriage, Cohabitation, and Childbearing." Journal of Economic Perspectives, 2016, 30(2), pp. 79-102; https://doi.org/10.1257/jep.30.2.79.

Murnane, Richard J. "US High School Graduation Rates: Patterns and Explanations." Journal of Economic Literature, 2013, 51(2), pp. 370-422; https://doi.org/10.1257/jel.51.2.370.

Pessin, Léa. "Changing Gender Norms and Marriage Dynamics in the United States." Journal of Marriage and Family, 2018, 80(1), pp. 25-41; https://doi.org/10.1111/jomf.12444.

Ramey, Valerie A. and Francis, Neville. "A Century of Work and Leisure." American Economic Journal: Macroeconomics, 2009, 1(2), pp. 189-224; https://doi.org/10.1257/mac.1.2.189.

Reid, Margaret Gilpin. Economics of Household Production. J. Wiley and Sons, 1934.

Santos, Cezar, and David Weiss. "Why Not Settle Down Already? A Quantitative Analysis of the Delay in Marriage." International Economic Review, 2016, 57(2), pp. 425-52; https://doi.org/10.1111/iere.12163.

Schneider, Daniel; Harknett, Kristen and Stimpson, Matthew. "What Explains the Decline in First Marriage in the United States? Evidence from the Panel Study of Income Dynamics, 1969 to 2013." Journal of Marriage and Family, 2018, 80(4), pp. 791-811; https://doi.org/10.1111/jomf.12481.

Stevenson, Betsey and Wolfers, Justin. "Marriage and Divorce: Changes and Their Driving Forces." Journal of Economic Perspectives, 2007, 21(2), pp. 27-52; https://doi.org/10.1257/jep.21.2.27. 